\title{
Genomic signatures of UV resistance evolution in Escherichia coli depend on the growth phase during exposure
}

S Selveshwari, Kasturi Lele, Sutirth Dey*

Population Biology Laboratory, Biology Division, Indian Institute of Science Education and Research, Pune, Maharashtra, India

*Name and address of the corresponding author:

Sutirth Dey

Biology Division

Indian Institute of Science Education and Research Pune

Dr Homi Bhabha Road

Pune, Maharashtra 411 008, India.

Tel.: +91 20 25908054; fax: +91 (20) 2590 8186;

e-mail: $\underline{\text { s.dey@iiserpune.ac.in }}$

Running title: Genomics of UV adaptation

Acknowledgements: We thank Gayathri Pananghat, Nishad Matange, Krishanpal Karmodiya, Farhat Habib, and Madhusudhan M. S. for their valuable inputs. SS was supported by a Junior Research Fellowship initially sponsored by IISER Pune and then by Department of Biotechnology (DBT), Govt. of India. KL was supported by a KVPY fellowship, sponsored by the Department of Science and Technology (DST), Govt. of India. This project was supported by a grant from Department of Biotechnology, Government of India (\#BT/PR22328/BRB/10/1569/2016) and internal funding from IISER Pune. The authors declare no conflict of interest. 
Title: Genomic signatures of UV resistance evolution in Escherichia coli depend on the growth phase during exposure

\begin{abstract}
:
Physiological states can determine the ability of organisms to handle stress. Does this mean that the same selection pressure will lead to different evolutionary outcomes, depending on the organisms' physiological state? If yes, what will be the genomic signatures of such adaptation(s)? We used experimental evolution in Escherichia coli followed by whole-genome whole-population sequencing to investigate these questions. The sensitivity of Escherichia coli to ultraviolet (UV) radiation depends on the growth phase during which it experiences the radiation. We evolved replicate $E$. coli populations under two different conditions of UV exposures, namely exposure during the lag and the exponential growth phases. Initially, the UV sensitivity of the ancestor was greater during the exponential phase than the lag phase. However, at the end of 100 cycles of exposure, UV resistance evolved to similar extents in both treatments. Genome analysis showed that mutations in genes involved in DNA repair, cell membrane structure and RNA polymerase were common in both treatments. However, different functional groups were found mutated in populations experiencing lag and exponential UV treatment. In the

former, genes involved in transcriptional and translational regulations and cellular transport were mutated, whereas the latter treatment showed mutations in genes involved in signal transduction and cell adhesion. Interestingly, the treatments showed no phenotypic differences in a number of novel environments. Taken together, these results suggest that selection pressures at different physiological stages can lead to differences in the genomic signatures of adaptation, which need not necessarily translate into observable phenotypic differences.
\end{abstract}

\title{
Keyword
}

Lag phase, Exponential phase, Evolve and resequence, UV damage, Antibiotic resistance 


\section{Introduction}

Environmental stresses can strongly influence the growth and physiology of microbial cells (Aertsen \& Michiels, 2004; Schimel et al., 2007). At the same time, antecedent growth conditions and physiology of the cells can influence a microbe's response to environmental stresses (Gilbert et al., 1990; Lindqvist \& Barmark, 2014; Lin \& Kussell, 2016). For example, it has been shown that the response of bacteria to ionizing radiations are influenced by both the growth phases during which the exposure happens as well as the physiology of microbial cells. The typical batch culture involves bacterial growth through three distinct growth phases: lag (where cells adapt to the new growth conditions), exponential (characterized by rapid cell division) and stationary phase (where growth plateaus as a result of nutrient depletion) (Monod, 1949). Among the three growth phases, the fast dividing cells (in exponential phase) have been shown to be more resistant to ionizing radiations than growth arrested and non-dividing cells (in stationary phase) in Moraxella spp. (Keller \& Maxcy, 1984), Lactobacillus spp. (Hastings et al., 1986), Halobacterium spp. (Kottemann et al., 2005; DeVeaux et al., 2007), and yeast (Fabre, 1970). However, the converse has also been observed in species like Escherichia coli (Morton \& Haynes, 1969; Dantur \& Pizarro, 2004; Bucheli-Witschel et al., 2010), Cronobacter sakazakii (Arroyo et al., 2012), and Salmonella typhimurium (Child et al., 2002). Although the effects of radiation on the exponential phase and the stationary phase have been explored in detail in the microbial literature, the same cannot be said about another important part of the microbial growth curve, namely the lag phase. Lag phase represents the adaptive period where the cells are metabolically active, but cell division has not begun (Rolfe et al., 2012). Study of this phase of growth has a number of implications including food preservation (Sun, 2011), bacterial infections and antibiotic resistance (Frimodt-Møller et al., 1983) as well as in maintaining laboratory cultures. Several environmental and physiological attributes that are unique to the lag phase (Bertrand, 2019 and the references therein) can influence the response to radiation stress (Gayán et al., 2014). For example, microbes in lag phase express distinctive transcriptomic and proteomic profiles which include components essential for metabolism and growth (Rechinger et al., 2000; Hornbæk et al., 2004; Larsen et al., 2006) as well as genes and proteins involved in repair of stasis induced macromolecular damages (Rolfe et al., 2012). This increased expression of DNA repair machinery in the lag phase might influence the cells' response to radiation. 
Consequently, the physiological state of the cell can influence its sensitivity to radiation both in the short term as well as over longer, evolutionary timescales.

Experimental evolution of resistance to ultraviolet radiation have been demonstrated in several microbial species including Escherichia coli (Ewing, 1995; Alcantara-Diaz et al., 2004; Goldman \& Travisano, 2011; Shibai et al., 2017), Salmonella typhimurium (Davies \& Sinskey, 1973), Bacillus subtilis (Wassmann et al., 2010), Pseudomonas cichorii (Weigand \& Sundin, 2009), and T7 bacteriophage (Tom et al., 2018). Although all these studies found that repeated exposures to UV resulted in increased ability to survive UV stress, there were several differences in the correlated responses to selection. For example, the increase in UV resistance was accompanied by increased cell size (Goldman \& Travisano, 2011), increased tolerance to osmotic, oxidative and desiccation stress (Wassmann et al., 2010), and the appearance and maintenance of rare colony morphologies due to increased rate of UV induced mutations (Weigand \& Sundin, 2009). These studies on evolution of radiation resistance looked at the effects of exposure either during the lag phase (Ewing, 1995; Weigand \& Sundin, 2009; Goldman \& Travisano, 2011; Shibai et al., 2017) or the stationary phase (Davies \& Sinskey, 1973; Alcantara-Diaz et al., 2004; Wassmann et al., 2010). Consequently, there is little understanding of the evolutionary effects of exposure during the exponential phase. At the same time, these existing studies have primarily focused on the evolution of resistant phenotypes and the correlated phenotypic changes (but see Shibai et al., 2017 and Tom et al., 2018). The genomics of radiation resistance has been studied in detail in radio-resistant species such as Deinococcus spp. (White et al., 1999; Blasius et al., 2008), Rhodobacter spp. (Perez et al., 2017). However, there is relatively less work on this aspect in the context of non-radio-resistant species (although see Bruckbauer et al., 2019). It is not obvious that the insights gained about the genomic correlates of exposure to UV in the above radio-resistant species, would be applicable to other microbes. Thus, in order to unearth the putative mechanisms underlying evolution of radiation resistance, it is important to extend the genetic studies conducted in the radio-resistant species to other microbes.

In this study, we attempt to address some of these lacunae in our understanding of the evolution of radio-resistance, particularly ultraviolet radiation. First, we observe that our ancestral population of Escherichia coli are more sensitive to UV in the exponential phase than in lag 
phase. To study the evolutionary response to UV radiation in these two phases, we subjected two sets of replicate populations to 100 rounds of UV exposure and growth in the lag and the exponential phases. Both treatments showed significant reduction in sensitivity to UV compared to control populations. However, growth phase differences in UV sensitivity were no longer observed. To investigate the genomic correlates of evolution of UV resistance, the UV-treated and control populations were further subjected to whole-genome whole-population sequencing. Genes associated with DNA repair pathways, RNA polymerase and cell membrane structure were commonly mutated in both UV-treated populations. Additionally, mutations in the populations exposed to UV in the lag phase were grouped in genes involved in transcription / translation regulation and cellular transport. On the other hand, only the populations that faced UV in the exponential phase contained mutations in signal transduction and cell adhesion. The genes and pathways that were mutated during UV resistance evolution may also have led to correlated changes in growth and survival in novel environments such as antibiotics, heavy metal salts and minimal media with a single carbon source. Contrary to our expectation, these differences in the genome did not translate to phenotypic differences between lag and exponential treatments in either the selection or the novel environments.

\section{Materials and Methods}

We used an Escherichia coli K12 MG1655 strain in which the lacY gene had been replaced with a Kanamycin resistance gene. Colonies of this bacterium are white coloured on MacConkey's agar as opposed to the red coloured colonies produced by other Escherichia coli. All cultures were maintained at $37^{\circ} \mathrm{C}$ and $150 \mathrm{RPM}$ throughout the selection and assays, except where stated otherwise. An overview of the experimental design is given in a supplementary figure (Figure S1).

\subsection{Experimental evolution}

Six populations were initiated from six independent $E$. coli colonies picked from a nutrient agar streaking of the ancestral E. coli strain. These six are henceforth referred to as the ancestor populations. From each ancestor, we derived three replicate populations and assigned them 
randomly to one of the three selection regimes, namely lag, exponential and control. Both lag and exponential treatments were subjected to UV during the respective growth phases while the control was devoid of UV exposure. The populations were exposed to UV in a custom-built dark chamber where the only source of light was an 8W UV-C tube-light (Philips TUV 8W) with an emission peak at $254 \mathrm{~nm}$. The lamp was placed at a height of 18 inch from a platform shaker, which results in a constant irradiance of $100.5 \mu \mathrm{W} / \mathrm{cm}^{2}$. At the beginning of the experiment, the duration of exposure was 15 seconds, which resulted in $2-3 \log _{10}$ reduction $(100-1000$ fold $)$ in colony forming units (CFUs); see section 2.2 for more details regarding estimation of $\log _{10}$ reduction. To allow sufficient time for the populations to adapt, the duration of UV exposure was increased gradually i.e., once every 5 days. For the full trajectory of exposure duration throughout selection, from day 0 - 100, see supplementary table (Table S2). By the end of 100 days of evolution, the exposure time was 370 seconds, i.e. an increase of $\sim 25$ times.

All cultures were grown in $2 \mathrm{ml}$ nutrient broth with kanamycin $\left(\mathrm{NB}^{\mathrm{Kan}}\right)$ in six-well tissue culture plates (see supplementary Table S3 for composition). The use of six-well plates allowed for a larger surface area to volume ratio for better UV penetration. Growth of all populations reached a plateau within 24 hours. Every 24 hours, $20 \mu \mathrm{l}$ of the grown culture was sub-cultured into fresh $\mathrm{NB}^{\mathrm{Kan}}$. Control populations $(\mathrm{C})$ were sub-cultured in $\mathrm{NB}^{\mathrm{Kan}}$ with no UV exposures whereas, populations designated as Lag (L) treatment were exposed to UV during the lag phase, immediately after subculture $(0 \mathrm{~h})$. Exponential (E) treatment populations were exposed to UV during the exponential phase by monitoring their growth/OD 600 in a plate reader (Synergy HT, BIOTEK Winooski, VT, USA) at 20-minute intervals. Based on pilot experiments, the exponential phase was deemed to have been reached when the $\mathrm{OD}_{600}$ of the culture was greater than 0.11 and the difference between two consecutive OD measurements were greater than $5 \%$ for the first time, i.e. $\mathrm{OD}_{\mathrm{t}+1}>1.05 \times \mathrm{OD}_{\mathrm{t}}$, where the subscript $\mathrm{t}$ and $\mathrm{t}+1$ refer to two successive time points. Populations in the exponential treatment were exposed to UV only when both the conditions were met. The 6-well plates containing the cultures were placed on the shaker platform directly under the UV lamp without the lid. The cultures were shaken at room temperature and 150 RPM during exposure. Since bacteria possess the photoreactivation pathway which can induce error-free reversal of UV induced damages and reduce the efficiency of UV radiation (Thoma, 1999; Sinha \& Hader, 2002), the cultures were maintained in darkness throughout the process of selection, except during sub-culturing. The UV induced mortality 
makes it impossible to accurately estimate the dilution ratio and consequently the number of generations in the UV-treated populations. However, at the end of 100 days, the UV-treated populations would have experienced more generations, on average, than control populations which underwent $\sim 667$ generations of evolution (6.67 doublings/transfer x 100 days). Every 5 days, $15 \%$ glycerol stocks ( $300 \mu \mathrm{l}$ of $50 \%$ glycerol $+700 \mu \mathrm{l}$ culture) of all populations was prepared and stored at $-80^{\circ} \mathrm{C}$. Due to logistic reasons, selection was interrupted once at day 60 . Selection was reinitiated by reviving $10 \mu 1$ glycerol stocks of all populations (UV-treated and controls) in $90 \mu \mathrm{l} \mathrm{NB}{ }^{\mathrm{Kan}}$ in a 96 well plate for 12 hours. $20 \mu \mathrm{l}$ of this revived culture was inoculated in $2 \mathrm{ml} \mathrm{NB}^{\mathrm{Kan}}$ to initiate day 61 . Glycerol stocks prepared at the end of 100 days, were used for all assays.

\subsection{Measuring UV sensitivity}

Sensitivity to UV induced mortality was measured as the log of change in number of colony forming units (CFUs) before and after UV exposure ( $\log _{10}$ (CFUs before exposure/CFUs after UV exposure)) (Koivunen \& Heinonen-Tanski, 2005).The populations to be assayed were revived by inoculating $5 \mu \mathrm{l}$ of the corresponding glycerol stocks in $2 \mathrm{ml} \mathrm{NB}^{\mathrm{Kan}}$ and incubating them overnight at $37^{\circ} \mathrm{C}$. Assays were conducted in six well plates with $20 \mu \mathrm{l}$ of the revived culture inoculated in $2 \mathrm{ml} \mathrm{NB}{ }^{\mathrm{Kan}}$. UV sensitivities of all populations were assayed in both lag and exponential phase where the UV exposures were carried out in a manner similar to the selection procedure. CFU counts before and after exposure were determined by serially diluting the cultures and plating $100 \mu \mathrm{l}$ of the appropriate dilutions (to obtain countable number of colonies) on $2 \%$ nutrient agar containing kanamycin $\left(\mathrm{NA}^{\mathrm{Kan}}\right)$. The serial dilution and plating after UV exposure was carried out in a dark room illuminated by red light to prevent photo-reactivation. The $\mathrm{NA}^{\mathrm{Kan}}$ plates were incubated in darkness at $37^{\circ} \mathrm{C}$, overnight and the number of colonies were counted manually and multiplied by the dilution factor to obtain the number of CFUs.

To measure the UV sensitivities of the ancestors, all six ancestral populations were assayed at both lag and exponential phase and at four exposure durations: 15, 60, 200, and 370 seconds. After 100 rounds of selection for UV resistance, we measured the UV sensitivity of the evolved populations $\mathrm{L}$, E, and $\mathrm{C}$ along with the ancestors. $\log _{10}$ reduction in CFUs during both lag and exponential growth phases was measured at exposure duration of 370 seconds. Two independent 
measurement replicates of the UV sensitivities of the evolved populations were obtained by conducting the entire assay from revival to CFU counts, twice. The relative change in UV sensitivity due to selection was obtained by scaling the sensitivities of the evolved populations by the sensitivity of the ancestors in the corresponding growth phases.

\subsection{Whole-genome sequencing and analysis}

To understand the genomics of repeated exposures to UV and selection for UV resistance, we randomly chose two replicates (rep 1 and 3) of the evolved populations (L, E, C), and their corresponding ancestors, and subjected them to whole-genome whole-population sequencing. 5 $\mu l$ of the corresponding glycerol stocks were inoculated in $4 \mathrm{ml} \mathrm{NB}^{\mathrm{Kan}}$ and incubated overnight at $37^{\circ} \mathrm{C} .3 \mathrm{ml}$ of the revived cultures were centrifuged down, washed twice in phosphate buffer saline (PBS), air dried and shipped for genome sequencing to a commercial service-provider. They performed paired-end whole-genome sequencing on NextSeq500 platform (Illumina, USA) at $\sim 100 \mathrm{X}$ (range: $98.8 \mathrm{X}-139.2 \mathrm{X}$ ) coverage and 150bp read length. The service-provider provided us with high quality reads after removing adaptor sequence, ambiguous reads (reads with unknown nucleotide "N" of more than 5\%), and low-quality sequences (reads with more than $10 \%$ having a phred score <20) using Trimmomatic v0.38. We then used Breseq version 0.33.2 pipeline (Deatherage \& Barrick, 2014) at default parameters for sequence alignment and variant calling. First, mutations in the ancestral genome were identified (in consensus mode) by aligning it to the reference genome of Escherichia coli MG1655 (Genbank accession: NC_000913.3). Breseq's gdtools package was used to incorporate the predicted mutations and update the ancestral genome. This updated ancestral genome sequence was then used as reference for alignment and variant calling (in polymorphism mode) in the evolved populations. Following previous studies (Bailey et al., 2015; Sandberg et al., 2017; Santos-Lopez et al., 2019), the list of predicted mutations were further curated by removing all variants present at frequencies less than $10 \%$. We also aligned the ancestral sequence in the polymorphism mode. To limit our analysis to the genomic changes that evolved de novo in response to selection, all polymorphic variants common between the ancestral and evolved populations were also removed from the dataset. This curated list of mutations was used for computing the number of SNPs and indels, SNPs in coding vs intergenic regions, synonymous vs nonsynonymous SNPs, as well as the mutational spectrum of all mutations. We estimated the $\mathrm{dN} / \mathrm{dS}$ ratio as the number of non- 
synonymous mutations per non-synonymous site $(\mathrm{dN})$ to the number of synonymous mutations per synonymous sites $(\mathrm{dS})$. The total number of non-synonymous and synonymous sites in the genome was estimated by using Breseq's gdtools package. Note that the relationship between $\mathrm{dN} / \mathrm{dS}$ ratio and the selection coefficient can be an issue when comparing two populations sharing a number of fixed mutations. However, this issue is avoided in our study as we compare evolved populations with their ancestors (Chen \& Zhang, 2020). Functional annotations and enrichment analysis of the genes were carried out on DAVID v.6.8 (Huang et al., 2009; Sherman \& Lempicki, 2009) a web-based bioinformatics application. The list of mutated genes was classified into functional groups (based on UniProtKB keywords) followed by manual curation.

\subsection{Measuring fitnesses in novel environment}

We observed that the UV-treated populations had accumulated numerous mutations across the genome. These UV induced mutations could possibly affect the fitness of the populations under environmental conditions not faced during selection (see Discussion for details). Therefore, after 100 days of selection for UV resistance, we assayed the fitness of the evolved populations (L, E, C) as change in minimum inhibitory concentration (MIC) and growth rate in a suite of environments.

\section{Measuring minimum inhibitory concentrations}

MICs of the evolved populations were measured in four antibiotic environments and three heavy metal environments. Antibiotics (ampicillin, chloramphenicol, nalidixic acid and rifampicin) from four different classes were chosen for their different mechanisms of action (Kohanski et al., 2010). Similarly, the heavy metal salts (cobalt chloride, copper sulphate and nickel chloride) were chosen for the different ways in which they disrupt metabolic processes (Dupont et al., 2011; Macomber \& Hausinger, 2011; Majtan et al., 2011). To the best of our knowledge, evolution of resistance to UV has no known association to fitness in these environments.

Populations were grown in increasing concentrations of the assay environment (antibiotics or heavy metals), and the minimum concentration at which no visible growth was obtained was taken as MIC. The evolved populations and their corresponding ancestor were revived as mentioned before. A gradient of the assay environments was prepared by serial two-fold 
dilutions in 96 well plates. The revived cultures were inoculated in each concentration of the assay environment at a dilution of 1/1000 in triplicates. After 48 hours of growth, each plate was scored for absence of growth either visually (for antibiotic environments) or when $\mathrm{OD}_{600}<0.2$ (for heavy metals). A concentration was considered the MIC of the population only if at least two out of the three replicates showed no growth. The entire assay from revival to MIC determination was repeated twice and served as measurement replicates. MIC of all the evolved populations were scaled by the MIC of their corresponding ancestor to obtain the change in MIC due to selection.

\section{Measuring growth rate}

Growth rates of the evolved populations were assayed under two kinds of conditions: a) in nutrient broth, and b) in M9 minimal media containing a single carbon source (for composition, see supplementary Table S4). Growth rate was measured in five different carbon sources: fructose, glucose, glycerol, mannose and thymidine, all of which feed into the glycolysis pathway via different intermediates (Voet \& Voet, 2011). Mutations in the intermediate enzymatic steps can likely alter the efficiency of metabolism of the carbon sources and consequently growth. The revived evolved and ancestral populations were inoculated in $200 \mu 1$ of the assay environment (i.e. M9 media containing one of the five carbon sources) at a dilution of 1/1000 in 96 well plates. These cultures were subjected to automated growth measurements using a plate reader (Synergy HT, BIOTEK Winooski, VT, USA). OD600 was measured every 20 minutes for 24 hours at $37^{\circ} \mathrm{C}$ and slow continuous shaking, at 17 cycles per second. Following previous studies (Karve et al., 2015; Sprouffske et al., 2018; Chavhan et al., 2019; RodríguezRojas et al., 2020), we computed the growth rate as the maximum slope of the curve over a moving window of 10 readings. Two measurement replicates were obtained by repeating the entire assay twice. The growth rates of the evolved populations were scaled by the ancestral growth rate to obtain the relative change in growth rate due to selection. 


\subsection{Statistical analysis}

Ancestral UV sensitivities were compared using a three-way mixed model ANOVA with randomized complete block design (RCBD) (Rohlf \& Sokal, 1980). Here, we used growth phase (lag and exponential) and exposure duration (15s, 60s, 200s, and 370s) as fixed factors crossed with each other and replicate populations (6 populations) as an independent random factor (neither crossed nor nested in other factors). Cohen's $d$ (Cohen, 2013) was computed to assess the effect sizes of the differences between the two growth phases. The effects sizes were interpreted as small, medium and large for $0.2<d<0.5,0.5<d<0.8$ and $d>0.8$, respectively (Sullivan \& Feinn, 2012). UV sensitivities of the evolved populations after 100 days of selection were compared in a three-way mixed model ANOVA with selection (lag, exponential and control) and assay environment (lag and exponential) as fixed factors and replicate populations (6 populations) as a random factor in a full factorial design. Fitness in novel environments were analyzed as separate two-way mixed model ANOVAs for each fitness measure and environment. Selection (lag, exponential and control) as fixed factors and replicate populations (6 populations) as a random factor were analyzed in a full factorial design. Correction for inflation of familywise error rate was done for the two fitness measurements, independently, using the Holm-Šidák procedure (Abdi, 2010).

We compared the $\mathrm{dN} / \mathrm{dS}$ ratio of the evolved populations to the expected ratio $(0.754$, ratio of possible synonymous sites to nonsynonymous sites in the genome computed using Breseq) using a binomial test on $\mathrm{R}$ 3.6.1.

All the ANOVAs were performed on STATISTICA v7.0 (Statsoft Inc.). Cohen's $d$ statistics were estimated using the freeware Effect Size Generator v2.3.0 (Devilly, 2004). 


\section{Results}

\subsection{Ancestral UV sensitivity in lag and exponential growth phases}

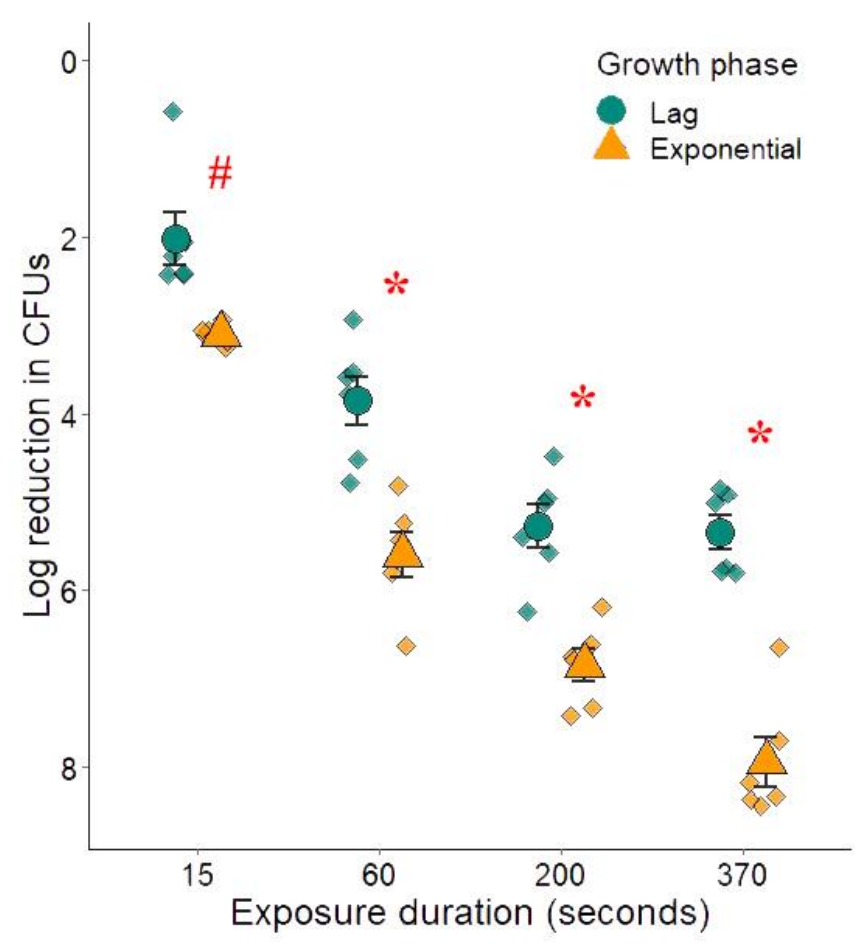

Figure 1. UV induced $\log _{10}$ reduction in CFUs during lag and exponential growth phases. UV sensitivity of the ancestral E.coli was measured at four exposure durations (15, 60, 200, and 370 seconds) and two growth phases. Mean sensitivity of the six ancestral populations are plotted as circles (lag phase) and triangles (exponential phase). Whiskers represent \pm SE. The scatter of the six ancestral value is represented by diamonds $(\diamond)$. ${ }^{*}$ denote $\mathrm{p}$ value $<0.05$ in Tukey's post-hoc analysis at that exposure value and \# denotes $\mathrm{p}=0.065$

We first measured the UV sensitivity of the ancestral Escherichia coli during the lag and exponential phases at four exposure durations. We found a significant interaction between growth phase and exposure duration $\left(F_{3,35}=3.34, P=0.03\right)$. The exponential phase sensitivity was significantly larger than the lag phase sensitivity in all but one comparison in Tukey's post hoc analysis (Fig. 1; 60s: $\mathrm{p}=0.0005$; Cohen's $d=2.69$ (large), 200s: $\mathrm{p}=0.002$; Cohen's $d=2.93$ (large), 370s: $\mathrm{p}=0.0001$; Cohen's $d=4.4$ (large)). At 15 seconds of exposure, the difference between lag and exponential exposure was marginally non-significant but with a large effect size (Fig. 1; 15s: $\mathrm{p}=0.065$; Cohen's $d=2.09$ (large)). Additionally, the six ancestral populations show no significant differences in their UV sensitivity $(F 5,35=0.36, P=0.87)$. Together, this shows 
that our ancestral strain of E.coli was more sensitive to UV during exponential phase of growth. However, as the interaction of growth phase and exposure was significant, we refrain from interpreting the main effects.

\subsection{UV sensitivity of evolved populations}

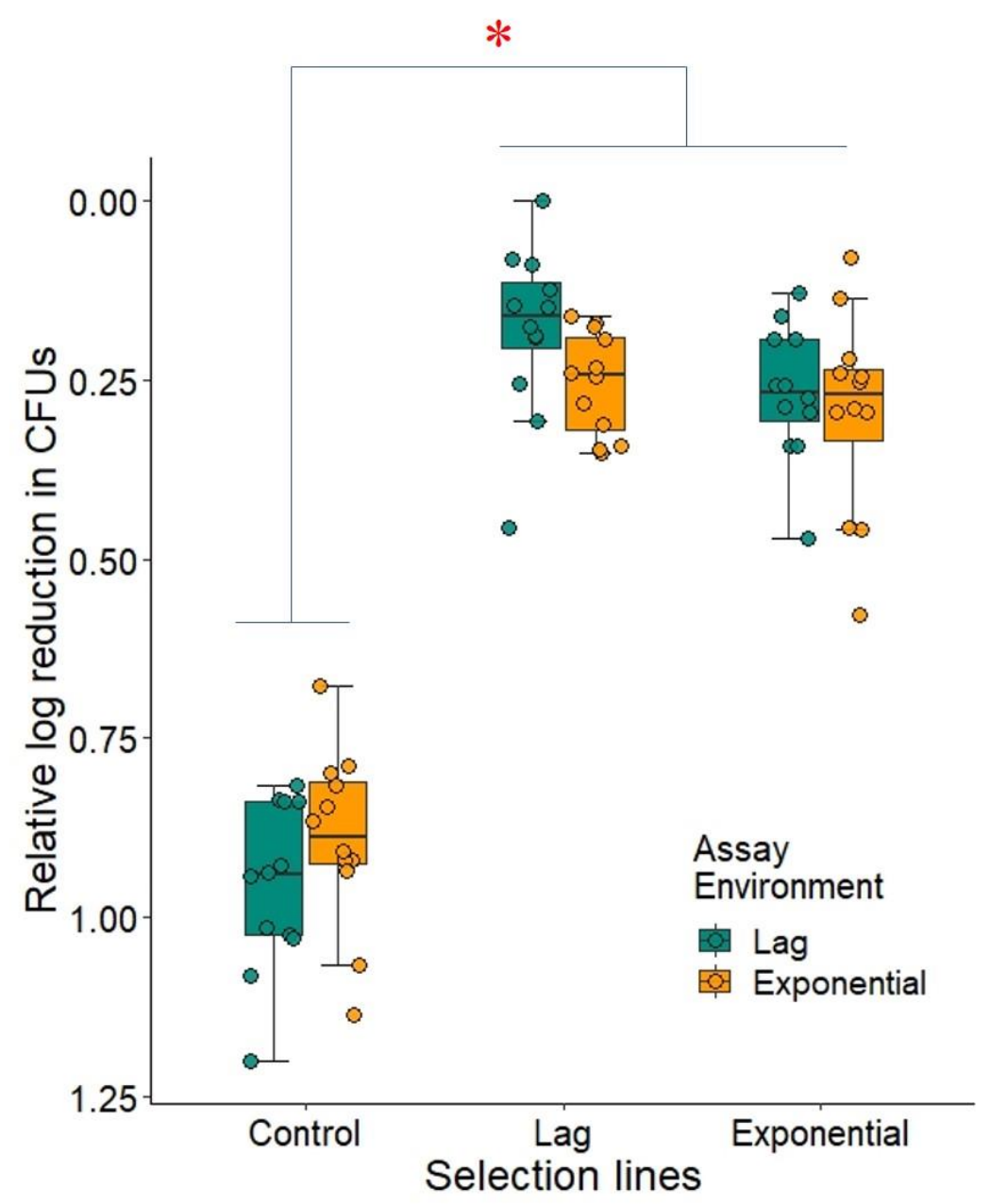

Figure 2. UV sensitivity of evolved populations relative to the ancestor's sensitivity. Decline in the relative $\log _{10}$ reduction (sensitivity to UV) in lag and exponential populations signifies evolution of resistance. Each box plot represents data from 12 values i.e., 6 replicate population assayed twice. Solid lines represent median, upper whisker denotes the largest data point lesser than or equal to $1.5 *$ IQR (inter-quartile range) and similarly for the lower whisker. * denotes that control population has significantly $(\mathrm{p}<0.05)$ lower resistance to UV than both lag and exponential populations in Tukey's post-hoc analysis. 
UV sensitivity of the evolved populations in the two growth phases were compared after scaling them by the corresponding ancestral values. At the end of 100 rounds of UV exposure and selection, the populations significantly differed in their relative UV sensitivities $\left(F_{2,36}=249.72\right.$, $P=2.91 \mathrm{E}-09)$. Tukey's post hoc analysis showed that both lag (L) and exponential (E) populations had evolved significantly higher resistance compared to control (C) populations but were not different from each other (Fig. 2; L and C $P=0.0001 ; \mathrm{E}$ and $\mathrm{C} P=0.0001$ and $\mathrm{L}$ and $\mathrm{E}$ $P=0.13)$. Interestingly, the interaction between selection lines and assay environments was also not significant $\left(F_{2,36}=3.82, P=0.059\right)$. This also suggests that the populations had evolved similar extents of resistance in both growth phases irrespective of the selection environment.

\subsection{Genomics of $U V$ resistance evolution}

To investigate the genomic changes accumulated during selection for UV resistance, we carried out whole-genome whole-population sequencing of two replicate populations from each selection regime (L, E, C) and their corresponding ancestors. Both our ancestral populations had nearly identical sequences. However, our lab strain differed from E.coli K-12 reference genome (NC_000913.3) at several genome locations. Therefore, we used the assembled sequences of the corresponding ancestor as reference for identifying mutations in the evolved populations. Exposure to UV in both growth phases resulted in a marked increase in the total number of mutations. The two replicates of lag (193 and 317) and exponential $(60,319)$ treatments had much greater number of single nucleotide polymorphisms (SNPs) compared to the control populations $(8,13)$. A histogram showing the distribution of mutation frequencies of all SNP in the four UV-treated populations is given in the supplementary figure S8. Very few indels (insertions and deletions) were identified in all three evolved populations (2, 2 in lag, 4,12 in exponential and 3,7 in control). Some of these indels, 0 (L1), 1 (L3, E1, E3), 2 (C1) and 5 (C3), were found to be mediated by IS2 insertional elements.

We also found that the mutational spectra of both lag and exponential treatments were transitionbiased as $\mathrm{GC} \rightarrow \mathrm{AT}$ transitions accounted for at least $50 \%$ of all mutations, a confirmed signature of exposure to UV (Fig. 3) (Griffiths et al., 2005; Brash, 2015). In spite of the bias, all six mutations types were represented in both UV treatments. Mutations in the control populations were confined to three or four types only (see supplementary table S5). 


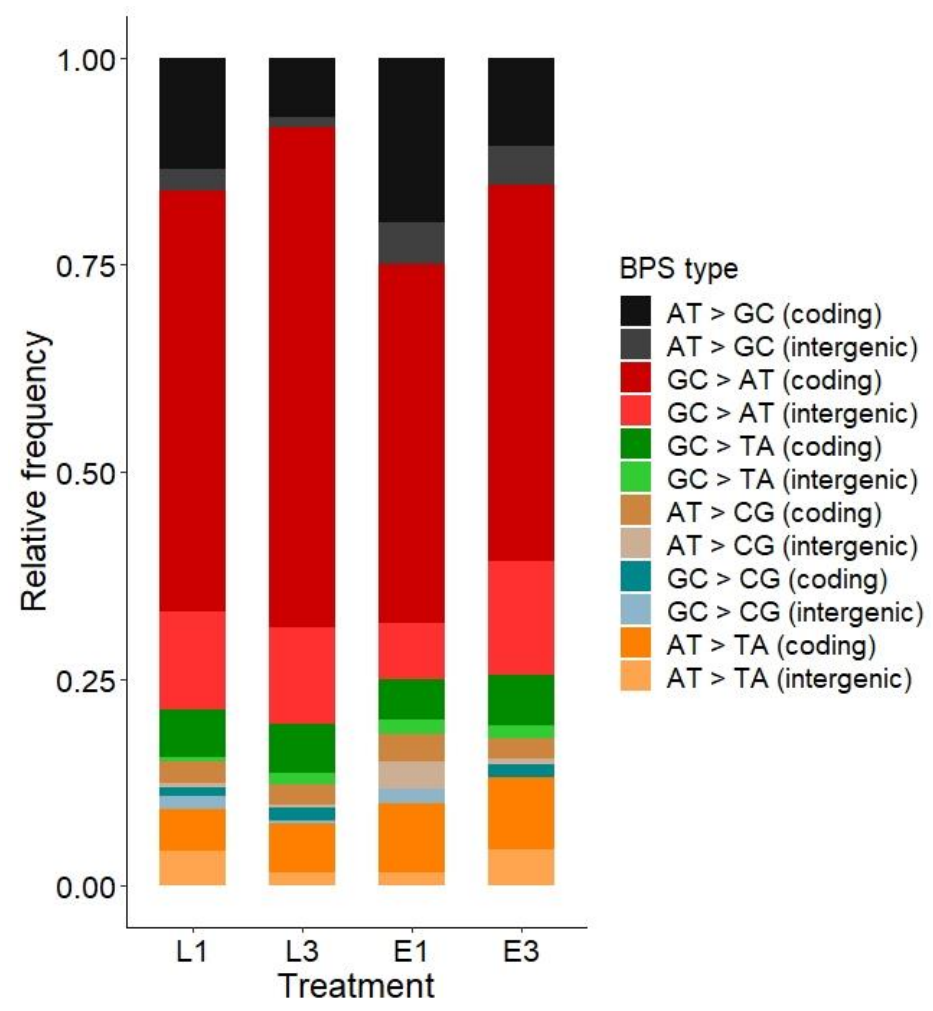

Figure 3: Mutational spectrum of SNPs accumulated during lag and exponential UV exposure. Colours in the stacked bar represent the relative frequency of each of the six type of base-pair substitutions (BPS), in the coding and intergenic regions..

We notice that $75-80 \%$ of all SNPs in the UV treatments were found in the coding regions which typically makes up about $88 \%$ of the Escherichia coli genome (Rogozin et al., 2002). We estimated the $\mathrm{dN} / \mathrm{dS}$ ratio (ratio of non-synonymous mutations per non-synonymous sites to synonymous mutations per synonymous sites) to infer the selection pressure that led to the genomic changes. Table 1 summarizes the $\mathrm{dN} / \mathrm{dS}$ ratios in the evolved populations. The ratios were statistically significant in both the lag treatments (L1, L3) and one of the exponential treatment (E3). In all three cases, the ratios were less than unity, indicating that these populations were primarily subjected to purifying selection (Yang \& Bielawski, 2000). 


\begin{tabular}{|c|c|c|}
\hline Population & dN/dS ratio & p value \\
\hline L1 & 0.665 & 0.023 \\
\hline E1 & 0.877 & 0.737 \\
\hline C1 & 0.652 & 0.571 \\
\hline L3 & 0.632 & $6.0 \mathrm{E}-4$ \\
\hline E3 & 0.469 & $2.75 \mathrm{E}-8$ \\
\hline C3 & 0.489 & 0.274 \\
\hline $\begin{array}{l}\text { Table 1: Estimates of non-synonymous mutation to synonymous mutation ratio in the evolved populations. } \\
\text { p value denotes the binomial probability that the observed dN/dS ratio differs from the expected ratio } \\
\text { (0.754), ratio of possible synonymous sites to nonsynonymous sites in the genome) }\end{array}$ \\
\hline
\end{tabular}

Next, we investigated the genetics of UV resistance evolution by considering only the nonsynonymous mutations in the UV-treated populations. To begin with, the genes that were mutated differed considerably between lag and exponential treatments (see supplementary file S9 for full list of non-synonymous mutations). There were only two genes (recA and mepS) that had mutated in both treatments but not in the control populations. Our ancestral populations had a single mutation in recA (G161D) with respect to the reference MG1655 strain. Reversion of this mutation had fixed in all UV-treated populations but not the controls. We note that this reversion in $\operatorname{rec} A(\mathrm{D} 161 \mathrm{G})$ is the only consistent mutation where all treatments have the same amino acid change. In addition to this, one other mutation (P314L) in recA was present at low frequency in L3. recA is involved in DNA recombination and repair (Smith et al., 1987; Schlesinger, 2007) and also plays an integral role in the mediation of SOS response (Markham et al., 1985; Maslowska et al., 2019). The second commonly mutated gene was mepS with four different mutations: Y82I (in E1), R83C (in L1), P111L (in L3, E3), and T114I (in L3). mepS is known to be involved in peptidoglycan biosynthesis during cell growth (Singh et al., 2012). Populations L1 and E3 had mutations in recJ and L3 had mutation in recQ, both components of the recFOR recombination pathway. Similarly, RNA polymerase genes rpoC was mutated in L1 and E3 population, while mutation in rpoB was observed n L3.

Besides these commonly mutated genes, we also identified 9 genes that were mutated in both the replicates of lag treatment. Of these, a functional cluster of 5 genes was identified. crp, deoR, 
$f a d R, h f q$, and lexA are known to be involved in DNA-binding, transcription and translational regulation. Additionally, lexA in association with $\operatorname{rec} A$, is known to mediate the SOS response. The remaining four genes show no obvious clustering (see Table 2 for full functional annotations). Similarly, in the populations exposed to UV during the exponential phase, we identified four genes that were mutated in both replicates. However, these genes too showed no obvious clustering of function (Table 2).

\section{Lag treatment}

\begin{tabular}{|l|l|}
\hline Gene & Functional annotation \\
\hline $\begin{array}{l}c r p \\
d e o R \\
f a d R \\
h f q \\
\text { lexA }\end{array}$ & \\
\hline lexA $($ recA $)$ & DNA-binding proteins, Repressors, Transcription and translational regulation \\
\hline$a d i A$ & SOS response \\
\hline$f d o G$ & Arginine catabolic processes \\
\hline$f r l D$ & Cellular respiration \\
\hline$y c b K$ & Carbohydrate phosphorylation \\
\hline & Uncharacterised protein \\
\hline &
\end{tabular}

\section{Exponential treatment}

\begin{tabular}{|l|l|}
\hline Gene & Functional annotation \\
\hline fimA & Cell adhesion \\
\hline phoR & Response to phosphate starvation and signal transduction \\
\hline ygfS & Oxidation-reduction process \\
\hline yoaE & Membrane component \\
\hline \multicolumn{2}{|l|}{} \\
\hline $\begin{array}{l}\text { Table 2: List of genes consistently mutated in both replicates of lag and exponential treatments. The genes along } \\
\text { with their functional annotations are listed. }\end{array}$
\end{tabular}


Using DAVID v.6.8, a web-based bioinformatics application, we carried out functional annotation and enrichment analysis of the list of non-consistent mutations. Only about half the list of genes fell into clusters of groups having similar functions (Fig. 4). This could have resulted in the observed lack of significance in enrichment analysis (supplementary Table S6). However, functional clusters comprising genes involved in or a part of cell membrane, were represented in three out of four populations (L1, L3, and E3). This, in addition to the fact that mutations of mepS were consistent across treatments, can suggest that cell membrane modification may play an important role in evolution of UV resistance. A second major group, that was found to be common between the two replicates of lag treatment, consisted of genes involved in transmembrane transport. Aside from these, mutations in lag treatment were grouped by genes involving in ligase activity, acetylation, tRNA-binding, nucleotide binding, and exopolysaccharide synthesis (Figure 4 and supplementary Table S6). Similarly, mutations in exponential treatments were grouped by genes involved in metal-ion binding, nucleotide binding, pyridoxal phosphate binding, kinase, and serine esterase. These differences imply that selection for UV resistance at the two growth phases can result in differences in how and where mutations accumulate in the genome. 


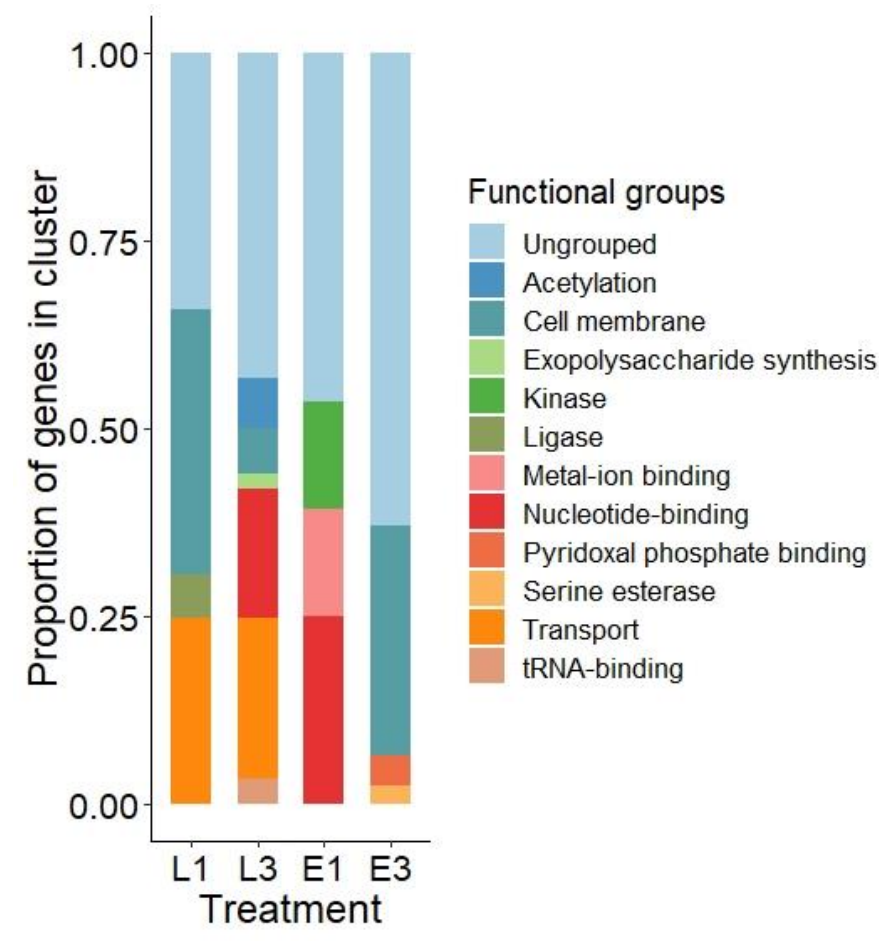

Figure 4: Functional grouping of non-consistent mutations. The functional categorizations are based on uniprot keywords and GO terms. Height of each stack represents the proportion of genes in that particular functional group. Functional annotation was done using DAVID v.6.8 followed by manual curation. See supplementary material Table S6 for list of genes in each group.

To summarize, repeated exposure to UV resulted the accumulation of a large number of mutations despite the effects of purifying selection. While genes such as recA and mepS were commonly mutated in all UV-treated populations, genes of different functional classes were mutated in lag and exponential treatments. This led us to the investigation of how these mutations affected the fitness of the populations under other environmental conditions. 


\subsection{Fitness in novel environment}

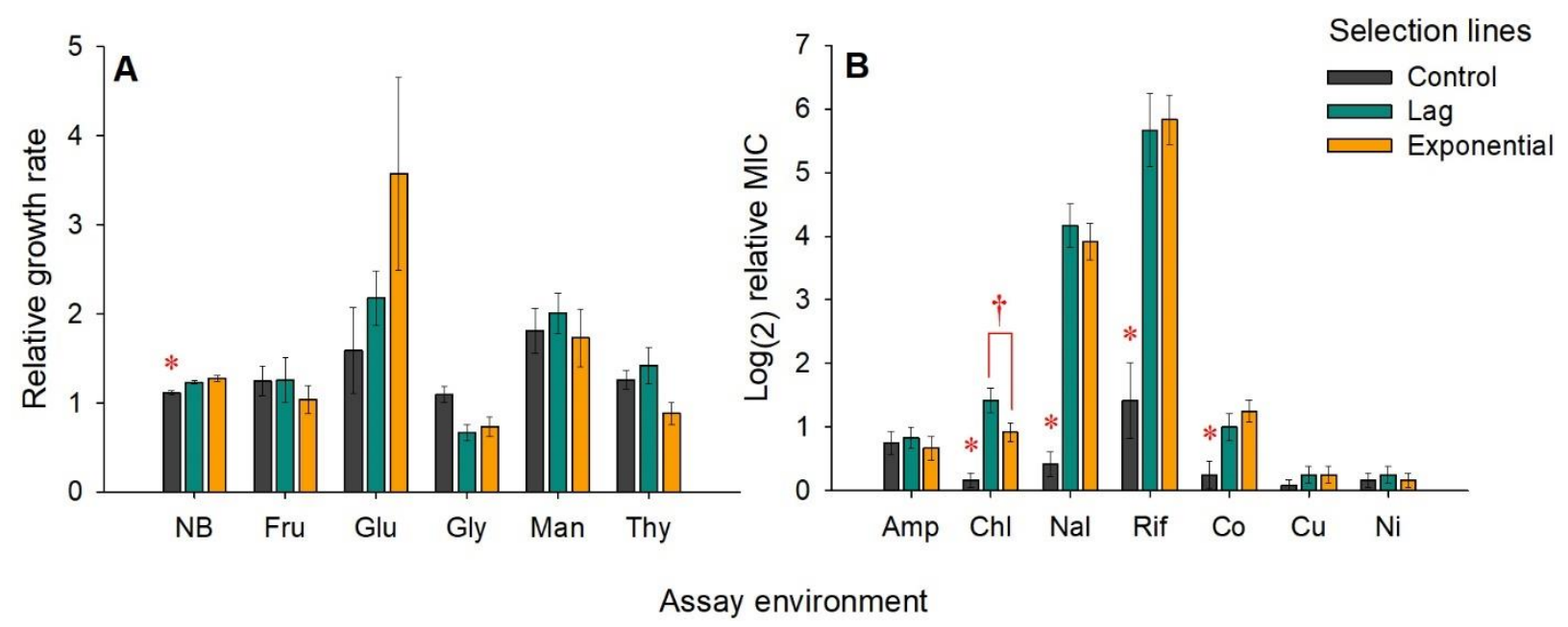

Figure 5: Relative fitness of the evolved populations in novel environment. Fitness is measured as (A) relative growth rate and (B) resistance, measured as minimum inhibitory concentration (MIC). Growth rate of the UVtreatedand control populations were assayed in nutrient broth (NB), M9 minimal media containing fructose (Fru), glucose (Glu), glycerol (Gly), mannose (Man) and thymidine (Thy). Resistance of all three evolved populations were measured in ampicillin (Amp), chloramphenicol (Chl), nalidixic acid (Nal), rifampicin (Rif), cobalt chloride (Co), copper sulphate $(\mathrm{Cu})$, and nickel chloride $(\mathrm{Ni})$. Fitnesses of the evolved populations were scaled by the ancestral fitness. Bars represents mean of 12 values i.e., 6 replicate populations assayed twice. Whiskers represent $\pm \mathrm{SE}$. * denote control is significantly (p value $<0.05$ ) less than lag and exponential in Tukey’s post-hoc analysis. $\dagger$ denotes significant differences between lag and exponential treatments.

Fitness of the evolved populations in novel environments was measured in two ways. Growth rate was measured in nutrient broth $\left(\mathrm{NB}^{\mathrm{Kan}}\right)$ and $\mathrm{M} 9$ minimal media in the presence of 5 different carbon sources: fructose (Fru), glucose (Glu), glycerol (Gly), mannose (Man) and thymidine (Thy). After correction for inflation of family-wise error rate (Holm-Šidák's correction) only NB showed a significant effect of selection (Fig. 5A: $F_{2,18}=17.04, P=0.0036$ ). Tukey's post-hoc analysis show that both lag and exponential treatments have increased growth rate in NB Kan compared to control populations but did not differ w.r.t each other. We also measured the resistance of evolved population in stress environments. Resistance was measured as change in MIC in 4 antibiotic environments: ampicillin (Amp), chloramphenicol (Chl), nalidixic acid (Nal), and rifampicin (Rif) and 3 heavy metal environments: cobalt chloride (Co), copper sulphate 
$(\mathrm{Cu})$, and nickel chloride (Ni). After correction for multiple testing (Holm-Šidák’s correction), main effect of selection was significant in chloramphenicol (Fig. 5B: $F_{2,18}=16.76, P=0.0037$ ), nalidixic acid $\left(F_{2,18}=70.33, P=9.02 \mathrm{E}-06\right)$, rifampicin $\left(F_{2,18}=16.37, P=0.0035\right)$, and cobalt chloride $\left(F_{2,18}=7.22, P=0.045\right)$. In all four cases, Tukey's post hoc tests suggested that lag and exponential treatments had increased MIC w.r.t control populations. Only in the case of chloramphenicol, there was a difference between lag and exponential populations: lag had higher MIC than exponential treatment $(P=0.046$ in Tukey's post hoc analysis). To further explore the difference in resistance between lag and exponential treatments, we also measured their growth rate at sub-MIC concentration $(0.5 \mu \mathrm{g} / \mathrm{ml})$ of chloramphenicol. The main effect of selection was significant (Fig. 6: $F_{2,18}=49.67, P=6.4 \mathrm{E}-06$ ) and both lag and exponential treatments had higher growth rate than control populations. But interestingly, populations in the exponential treatment had higher growth rate than those in the lag treatment $(P=0.0005$ in Tukey's post hoc analysis).

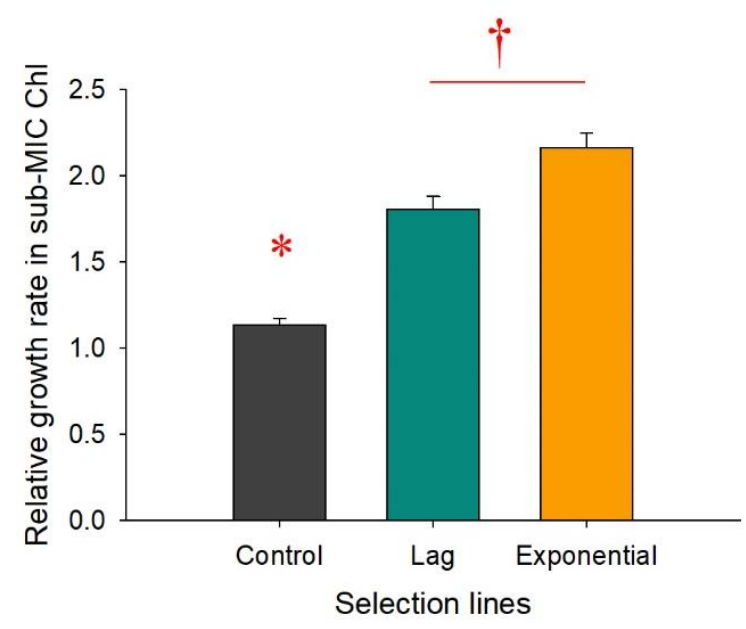

Figure 6: Relative growth rate of evolved populations in sub-MIC chloramphenicol. Bars represents mean of 12 values i.e., 6 replicate populations assayed twice. Whiskers represent \pm SE. * denote control is significantly (p value $<0.05)$ less than lag and exponential in Tukey's post-hoc analysis. $\dagger$ denotes significant differences between lag and exponential treatments in Tukey's post-hoc analysis. 
To summarize, the genomic changes due to selection for UV resistance did not result in fitness changes, between the treatments, in all but one novel environment. Interestingly, the genomic changes induced by selection under UV, never led to a decrease in fitness, w.r.t control populations, in the novel environments. In the case of chloramphenicol, where there was an observable phenotypic difference between the lag and the exponential treatments, the effect was not consistent as lag treatment had higher MIC whereas exponential treatment had higher growth rate. In other words, genomic differences between the populations that experienced selection in different growth phases did not translate into observable differences in their phenotypes, either in the selection environment (Figure 2), or in the novel environments (Figure 5).

\section{Discussion}

Bacterial growth phases show considerable variations in their resistance to ionizing radiations. While some studies have demonstrated that the exponential phase can have increased sensitivity to ionizing radiations (Morton \& Haynes, 1969; Child et al., 2002; Dantur \& Pizarro, 2004; Bucheli-Witschel et al., 2010; Arroyo et al., 2012), others have shown that this phase can have greater resistance to such radiations (Keller \& Maxcy, 1984; Hastings et al., 1986; Kottemann et al., 2005; DeVeaux et al., 2007; Sukhi et al., 2009). In this study, we compared the UV sensitivity of our ancestral strain of Escherichia coli MG1655 in lag and exponential phase. Ancestral cells in the exponential phase were more sensitive to UV, which resulted in larger reduction ( 1-2 $\log _{10}$ fold more reduction) in colony forming units (CFUs) compared to lag phase (Fig. 1). The two growth phases differ in a number of factors that can influence UV sensitivity. Factors such as changes in growth rate (Keller \& Maxcy, 1984; Berney et al., 2006; Bucheli-Witschel et al., 2010), growth environment (particularly nutrition availability post irradiation) (Child et al., 2002; Sukhi et al., 2009), and the quantity of genetic material (Fabre, 1970; Bucheli-Witschel et al., 2010), have been suggested to explain the differential UV sensitivity in different growth phases. These differences can influence the organisms' ability to repair UV induced damages and consequently the dynamics of resistance evolution.

We subjected our E.coli populations to selection under UV exposures during the lag and the exponential phase. After 100 rounds of exposure and growth, the UV exposed populations 
evolved increased resistance to UV compared to the non-exposed control populations (Fig. 2). 370 seconds of UV exposure in the ancestor and the control populations resulted in 5-7 $\log _{10}$ reduction in viable CFUs whereas the UV-treated populations experienced only 1-2 $\log _{10}$ reduction in CFUs (see supplementary material Table S7 for the raw data). Contrary to our expectations, the differences between growth phases observed in the sensitive strains (ancestor and control populations) did not translate into significant differences in the evolved response. Both the treatments had evolved resistance to UV in both growth phases, irrespective of the selection environment. These results are comparable with previous studies in Bacillus subtilis (Wassmann et al., 2011) where it was shown that populations that evolved UV resistance in the stationary phase, also showed similar increased UV resistance in all growth phases. Interestingly, in that study, this was observed in spite of the fact that their ancestral and control populations showed growth phase dependent sensitivity to UV (Wassmann et al., 2011). Considering the results from our study and Wassman et al., (Wassmann et al., 2011), it is tempting to hypothesize that there are only a few routes to UV resistance, which might not be influenced by the growth phases. To investigate this possibility, we employed evolve and resequence $(E \& R)$ technique on replicate populations to characterize the genomics of UV resistance at different growth phases.

Both the treatments saw the accumulation of a large number of mutations with an overrepresentation of $\mathrm{GC} \rightarrow \mathrm{AT}$ transitions (at least $50 \%$ of all mutations). $\mathrm{GC} \rightarrow \mathrm{AT}$ transitions are the signature mutations of UV (Griffiths et al., 2005; Brash, 2015) which are a result of the repair of UV-induced oxidative damages to the DNA (Wang et al., 1998). This demonstrates the strong influence of UV radiation in shaping the genome of the UV-treated populations.

To investigate the genomic changes associated with UV resistance, we focused on the nonsynonymous mutations in the populations. We found that a single amino acid change in $r e c A$ (D161G) was convergent across all four UV-treated populations. Our ancestor had a mutation in recA (G161D) with respect to the reference strain, MG1655 (NC_000913.3). It is known that D161 is an extremely conserved amino acid and it plays an important role in determining the preference of recA for single stranded DNA over double stranded DNA (Shinohara et al., 2015). The fact that all UV-treated populations, but not the controls, had fixed for reversion to the wild 
type form, suggests that this region is highly essential for the functioning of $\operatorname{rec} A$ in the presence of UV stress.

While recA protein is a key regulator of recombinational repair of UV induced damages (Smith et al., 1987) we did not find any other prominent change in its sequence. Interestingly, we found mutations in recJ and $\operatorname{rec} Q$ genes, which are components of the recFOR recombination machinery that is regulated by recA in response to DNA damage (Morimatsu \& Kowalczykowski, 2014). Additionally, mutations in the RNA polymerase (RNAP) genes, rpoB and rpoC, were also observed in UV-treated populations. Although mutation in rpoB gene are major effectors of rifampicin resistance, it was not observed in all populations. Since rifampicin resistance had evolved in both UV-treated populations, resistance cannot simply be explained by rpoB mutation. We also note that the mutation M1243L (in L3) is not one of the 69 known rpoB mutation conferring rifampicin resistance (Garibyan et al., 2003). However, mutations in RNAP have previously been shown to confer radiation resistance in Deinococcus (Bruckbauer et al., 2019). Studies show that RNAP and DNA repair proteins can interact when replication is stalled in rapidly dividing cells (Trautinger et al., 2005; Baharoglu et al., 2010). In our populations, we see an interesting combination of mutations in the recFOR pathway and RNAP genes. Mutations in rec $\mathrm{J}$ and $\mathrm{rpoC}$ were found together and at similar frequency in $\mathrm{L} 1$ and $\mathrm{E} 3$ populations while mutations in recQ and rpoB occurred together in L3, at similar frequency (see supplementary document S8). It is likely that the interaction between the different components of the two mechanisms (recFOR pathway and RNAP) is crucial for UV resistance. However, these components can interact in multiple ways and figuring out the details of these interactions is a challenge that is outside the scope of this study.

Although DNA/nucleotides are considered to be the primary target of UV radiation, there is growing evidence that cell membrane (Alper, 1977; Schwarz, 1998; Kumar et al., 2016) and proteins (Krisko \& Radman, 2010; Daly, 2012) are also indirect targets of UV damage via generation of reactive oxygen species (ROS). Prevention and/or tolerance to damages to the cell membrane and protein can be an alternate strategy of UV resistance. It has been shown that ROS generated by UVB stress causes lipid peroxidation resulting in cell membrane damage (Gomes et al., 2013; Santos et al., 2013). Thus, maintaining cell membrane integrity is probably one of the first priorities when under UV stress. For instance, in Enterobacter cloacae, outer membrane 
protein $(o m p C)$ and periplasmic oligopeptide binding protein (oppA) were among the differentially expressed genes when exposed to UVB (Kumar et al., 2016). Although a causal link between cell membrane structure and radiation resistance has not been experimentally shown, the highly radio-resistant Deinococcous spp. is well known for its unique multilayered (six layers) cell membrane (Makarova et al., 2001). Thus, it is possible that the structure and composition of the cell membrane might influence radiation resistance. Consistent with this, we see that all our UV-treated populations, but not the controls, carry mutations in mepS, an endopeptidase which is a part of cell wall biogenesis (Singh et al., 2012). Additionally, mutation clusters in genes involved in or a part of cell membrane structure were consistent among UVtreated populations (Fig. 4). With the present data, it is not possible for us to comment on whether these mutations directly led to increased UV resistance or were neutrally accumulated as a consequence of increased mutation rate in the UV-treated populations. However, this opens potential avenues for investigating the mechanism of UV resistance from the point of view of cell membrane structure and composition. It is also possible that the increased mutation supply in the UV treated populations allowed them to explore the mutation landscape for mutations that could be beneficial in the laboratory growth conditions. This is evident from the fact that both UV-treated populations had significant increase in growth rate in nutrient broth than the control populations (Fig. 5A).

One of the mechanisms of radiation resistance in Deinococcus is the export of damaged/degraded DNA following radiation (Battista, 1997; White et al., 1999). Transport of the damaged oligonucleotides can prevent them from being reincorporated during repair. While the cells export damaged DNA, nutrients such as amino acids, sugars and phosphates may also be imported into the cell (Makarova et al., 2001). This increased nutrition is essential for the energy expensive DNA repair process (Venkateswaran et al., 2000). Consequently, radioresistance has also been attributed to efficient transport of nutrients into the cell (Makarova et al., 2001; Child et al., 2002; Sukhi et al., 2009). In line with this, we observe clustering of mutations in genes involved in cellular transport (Fig. 4). These mutations are unique to the lag treatment and were not present in the exponential treatment. Another unique characteristic of the genome of the lag treatment is the fixation of mutations in lexA genes. lexA is a transcriptional repressor of SOS response (Maslowska et al., 2019). Additionally, mutations in transcriptional regulators such as crp, deoR, fadR, $h f q$ were also common in the lag populations (Table 2). Taken together, 
this suggests that in addition to the direct response to radiation, UV resistance in lag treatment can comprise of protection/tolerance mechanisms as well as indirect response via regulation of other genes.

The mutations in the exponential treatment, except for those in genes related to repair and cell membrane structure and function, could not be associated with any known pathway associated with UV resistance (Table 2 and Fig. 4). Characterizing the role of signal transduction, cell adhesion, metal-ion and nucleotide binding proteins, and enzymes such as kinases, and serine esterase, in the context of UV resistance, might suggest the association of novel pathways of UV resistance.

Horizontal gene transfer (HGT), by natural transformation of exogeneous DNA from the environment, is known to be induced by stress (Claverys et al., 2006; Prudhomme et al., 2006), particularly UV radiation (Charpentier et al., 2011). Additionally, bacterial competence is also known to be influence by multiple factors including, growth phase (Szostkova et al., 1999). However, exploring the influence of HGT on the genome evolution of our UV-treated populations was out of the scope of this study.

UV as a mutagen is expected to increase the genome wide mutagenesis. A large number of the resulting mutations are expected to be deleterious in the selection environment and therefore likely to be purged by purifying selection. The observed $\mathrm{dN} / \mathrm{dS}$ ratio of mutations in the coding region being less than one suggests that the UV-treated populations were indeed subjected to purifying selection (Table 1). The mutations that escaped being purged and accumulated to high frequencies were either beneficial or neutral in the selection environment. However, it is possible that some of these neutral mutations are contextually neutral, i.e. have an effect on fitness when the environment is altered (Wagner, 2005). To investigate this possibility, we studied the fitness of the UV-treated populations under various antibiotics, heavy metals and carbon sources. Despite the large genetic variation, fitness of the UV-treated populations were significantly different from the control populations in only four out of 12 novel environments namely, chloramphenicol, nalidixic acid, rifampicin and cobalt chloride (Figure 5). One possible way by which the UV-treated populations could have acquired resistance to these environments is via the UV induced alterations in the cell membrane permeability. Outer membrane permeability has 
previously been implicated in the evolution of antibiotic resistance (Delcour, 2009; Ghai \& Ghai, 2018; May \& Grabowicz, 2018). On the other hand, exposure to UV could have also resulted in the introduction of antibiotic resistance mutations in smaller subpopulations which could allow them to grow at higher concentrations of antibiotics (Band \& Weiss, 2019). Interestingly, the lag and exponential populations showed significant differences only in resistance to chloramphenicol. Even in terms of chloramphenicol resistance, the differences between lag and exponential treatments were not consistent across MIC and growth rate (Figures 5 and 6). Thus, taken together, the genomic signatures of UV adaptation in lag and exponential treatment populations did not result in any major phenotypic differences between them in both the selection as well as novel environments.

\section{Conclusion}

Experimental evolution in combination with high-throughput sequencing (evolve and resequence) is an extremely powerful tool to study the genomics of adaptation (Long et al., 2015; Schlötterer et al., 2015). While it is known that the phenotype-genotype map can be degenerate, molecular parallelisms can be found at different levels of genome organization ranging from same nucleotide substitution to similar gene networks (Rosenblum et al., 2014; Hao et al., 2019). Evidence for this comes from previous studies where huge diversity in the beneficial mutations have been reported at the level of nucleotides but convergence was observed at the level of genes and functional groups (Woods et al., 2006; Tenaillon et al., 2012). Similarly, in our study, although the large number of mutations initially seemed to be randomly distributed in the genome, we observed some convergence of functional groups. DNA repair, RNA polymerase and genes associated with cell membrane structure were some of the convergent changes observed in the UV-treated populations. However, the exposure to UV during different growth phases also led to some unique genomic signatures. It is likely that the two growth phases represent different physiological and biochemical environments inside the cell, which could have constrained the UV induced mutations and consequently the amount and nature of genetic variation available for selection to act. Nevertheless, mutations in genes for mechanisms besides DNA repair systems that have been observed in the UV-treated populations 
are suggestive of the role of other indirect pathways involved in UV resistance. These results are reminiscent of mechanisms of extreme radio-resistance in Deinococcus radiodurans R1 where resistance has been shown to rely more on indirect mechanisms such as cellular cleansing, signal transduction and transcriptional regulation than on extensive damage repair mechanisms (Makarova et al., 2001; Galperin et al., 2006; Blasius et al., 2008). In addition to recognizing the different possible mechanisms of UV resistance, this study highlights the influence of physiology in shaping the genomic evolution. We see that mutational profiles are dependent on the growth phase of exposure. Very little is known about such growth phase specific effect of most mutagens. Such physiological biases of mutagenesis can have important implications in industrial strain improvement studies. Additionally, as UV radiation is widely used as a disinfectant, it is important to acknowledge the evolution of antibiotic resistance as a correlated response. To better manage this, further experiments need to be done to understand the relationship between growth physiology, UV response and antibiotic resistance evolution. 


\section{Reference}

Abdi, H. 2010. Holm's sequential Bonferroni procedure. Encyclopedia of research design 1: 1-8.

Aertsen, A. \& Michiels, C.W. 2004. Stress and how bacteria cope with death and survival. Critical reviews in microbiology 30: 263-273.

Alcantara-Diaz, D., Brena-Valle, M. \& Serment-Guerrero, J. 2004. Divergent adaptation of Escherichia coli to cyclic ultraviolet light exposures. Mutagenesis 19: 349-354.

Alper, T. 1977. The role of membrane damage in radiation-induced cell death. In: Membrane toxicity, pp. 139-165. Springer.

Arroyo, C., Gayan, E., Pagan, R. \& Condon, S. 2012. UV-C inactivation of Cronobacter sakazakii. Foodborne pathogens and disease 9: 907-914.

Baharoglu, Z., Lestini, R., Duigou, S. \& Michel, B. 2010. RNA polymerase mutations that facilitate replication progression in the rep uvrD recF mutant lacking two accessory replicative helicases. Molecular microbiology 77: 324-336.

Band, V.I. \& Weiss, D.S. 2019. Heteroresistance: A cause of unexplained antibiotic treatment failure? PLoS pathogens 15.

Battista, J.R. 1997. Against all odds: the survival strategies of Deinococcus radiodurans. Annual review of microbiology 51: 203-224.

Berney, M., Weilenmann, H.-U., Ihssen, J., Bassin, C. \& Egli, T. 2006. Specific growth rate determines the sensitivity of Escherichia coli to thermal, UVA, and solar disinfection. Applied and environmental microbiology 72: 2586-2593.

Bertrand, R.L. 2019. Lag phase is a dynamic, organized, adaptive, and evolvable period that prepares bacteria for cell division. Journal of bacteriology 201: e00697-00618.

Blasius, M., Sommer, S. \& Hubscher, U. 2008. Deinococcus radiodurans: what belongs to the survival kit? Critical reviews in biochemistry and molecular biology 43: 221-238.

Brash, D.E. 2015. UV signature mutations. Photochemistry and photobiology 91: 15-26.

Bruckbauer, S.T., Trimarco, J.D., Martin, J., Bushnell, B., Senn, K.A., Schackwitz, W., Lipzen, A., Blow, M., Wood, E.A. \& Culberson, W.S. 2019. Experimental evolution of extreme resistance to ionizing radiation in Escherichia coli after 50 cycles of selection. Journal of bacteriology 201.

Bucheli-Witschel, M., Bassin, C. \& Egli, T. 2010. UV-C inactivation in Escherichia coli is affected by growth conditions preceding irradiation, in particular by the specific growth rate. Journal of applied microbiology 109: 1733-1744.

Charpentier, X., Kay, E., Schneider, D. \& Shuman, H.A. 2011. Antibiotics and UV radiation induce competence for natural transformation in Legionella pneumophila. Journal of bacteriology 193: 1114-1121.

Chavhan, Y.D., Ali, S.I. \& Dey, S. 2019. Larger numbers can impede adaptation in asexual populations despite entailing greater genetic variation. Evolutionary Biology 46: 1-13.

Chen, P. \& Zhang, J. 2020. Antagonistic pleiotropy conceals molecular adaptations in changing environments. Nature ecology \& evolution 4: 461-469.

Child, M., Strike, P., Pickup, R. \& Edwards, C. 2002. Salmonella typhimurium displays cyclical patterns of sensitivity to UV-C killing during prolonged incubation in the stationary phase of growth. FEMS microbiology letters 213: 81-85.

Claverys, J.-P., Prudhomme, M. \& Martin, B. 2006. Induction of competence regulons as a general response to stress in gram-positive bacteria. Annual review of microbiology 60.

Cohen, J. 2013. Statistical power analysis for the behavioral sciences. Routledge.

Daly, M.J. 2012. Death by protein damage in irradiated cells. DNA repair 11: 12-21. 
Dantur, K.I. \& Pizarro, R.A. 2004. Effect of growth phase on the Escherichia coli response to ultraviolet-A radiation: influence of conditioned media, hydrogen peroxide and acetate. Journal of Photochemistry and Photobiology B: Biology 75: 33-39.

Davies, R. \& Sinskey, A.J. 1973. Radiation-resistant mutants of Salmonella typhimurium LT2: development and characterization. Journal of bacteriology 113: 133-144.

Deatherage, D.E. \& Barrick, J.E. 2014. Identification of mutations in laboratory-evolved microbes from next-generation sequencing data using breseq. In: Engineering and analyzing multicellular systems, pp. 165-188. Springer.

Delcour, A.H. 2009. Outer membrane permeability and antibiotic resistance. Biochimica et Biophysica Acta -Proteins and Proteomics 1794: 808-816.

DeVeaux, L.C., Müller, J.A., Smith, J., Petrisko, J., Wells, D.P. \& DasSarma, S. 2007. Extremely radiationresistant mutants of a halophilic archaeon with increased single-stranded DNA-binding protein (RPA) gene expression. Radiation research 168: 507-514.

Devilly, G. 2004. The effect size generator for windows: Version 2.3 (computer programme). Centre for Neuropsychology, Swinburne University, Australia.

Dupont, C.L., Grass, G. \& Rensing, C. 2011. Copper toxicity and the origin of bacterial resistance-new insights and applications. Metallomics 3: 1109-1118.

Ewing, D. 1995. The directed evolution of radiation resistance in E. coli. Biochemical and biophysical research communications 216: 549-553.

Fabre, F. 1970. UV-sensitivity of the wild-type and different UVS mutants of schizosaccharomyces pombe Influence of growth stages and DNA content of the cells. Mutation Research/Fundamental Molecular Mechanisms of Mutagenesis 10: 415-426.

Frimodt-Møller, N., Sebbesen, O. \& Thomsen, V.F. 1983. The pneumococcus and the mouse protection test: importance of the lag phase in vivo. Chemotherapy 29: 128-134.

Galperin, M.Y., Moroz, O.V., Wilson, K.S. \& Murzin, A.G. 2006. House cleaning, a part of good housekeeping. Molecular microbiology 59: 5-19.

Garibyan, L., Huang, T., Kim, M., Wolff, E., Nguyen, A., Nguyen, T., Diep, A., Hu, K., Iverson, A. \& Yang, H. 2003. Use of the rpoB gene to determine the specificity of base substitution mutations on the Escherichia coli chromosome. DNA repair 2: 593-608.

Gayán, E., Condón, S. \& Álvarez, I. 2014. Biological aspects in food preservation by ultraviolet light: a review. Food and Bioprocess Technology 7: 1-20.

Ghai, I. \& Ghai, S. 2018. Understanding antibiotic resistance via outer membrane permeability. Infection and drug resistance 11: 523.

Gilbert, P., Collier, P.J. \& Brown, M. 1990. Influence of growth rate on susceptibility to antimicrobial agents: biofilms, cell cycle, dormancy, and stringent response. Antimicrobial agents and chemotherapy 34: 1865.

Goldman, R.P. \& Travisano, M. 2011. Experimental evolution of ultraviolet radiation resistance in Escherichia coli. Evolution 65: 3486-3498.

Gomes, M.C., Silva, S., Faustino, M.A., Neves, M.G., Almeida, A., Cavaleiro, J.A., Tomé, J.P. \& Cunha, Â. 2013. Cationic galactoporphyrin photosensitisers against UV-B resistant bacteria: oxidation of lipids and proteins by 102 . Photochemical \& Photobiological Sciences 12: 262-271.

Griffiths, A.J., Wessler, S.R., Lewontin, R.C., Gelbart, W.M., Suzuki, D.T. \& Miller, J.H. 2005. An introduction to genetic analysis. Macmillan.

Hao, Y., Qu, Y., Song, G. \& Lei, F. 2019. Genomic Insights into the Adaptive Convergent Evolution. Current genomics 20: 81-89.

Hastings, J., Holzapfel, W. \& Niemand, J. 1986. Radiation resistance of lactobacilli isolated from radurized meat relative to growth and environment. Appl. Environ. Microbiol. 52: 898-901. 
Hornbæk, T., Jakobsen, M., Dynesen, J. \& Nielsen, A.K. 2004. Global transcription profiles and intracellular $\mathrm{pH}$ regulation measured in Bacillus licheniformis upon external $\mathrm{pH}$ upshifts. Archives of microbiology 182: 467-474.

Huang, D.W., Sherman, B.T. \& Lempicki, R.A. 2009. Bioinformatics enrichment tools: paths toward the comprehensive functional analysis of large gene lists. Nucleic acids research 37: 1-13.

Karve, S., Daniel, S., Chavhan, Y., Anand, A., Kharola, S. \& Dey, S. 2015. Escherichia coli populations in unpredictably fluctuating environments evolve to face novel stresses through enhanced efflux activity. Journal of evolutionary biology 28: 1131-1143.

Keller, L.C. \& Maxcy, R.B. 1984. Effect of physiological age on radiation resistance of some bacteria that are highly radiation resistant. Appl. Environ. Microbiol. 47: 915-918.

Kohanski, M.A., Dwyer, D.J. \& Collins, J. 2010. How antibiotics kill bacteria: from targets to networks. Nature Reviews Microbiology 8: 423-435.

Koivunen, J. \& Heinonen-Tanski, H. 2005. Inactivation of enteric microorganisms with chemical disinfectants, UV irradiation and combined chemical/UV treatments. Water research 39: 15191526.

Kottemann, M., Kish, A., Iloanusi, C., Bjork, S. \& DiRuggiero, J. 2005. Physiological responses of the halophilic archaeon Halobacterium sp. strain NRC1 to desiccation and gamma irradiation. Extremophiles 9: 219-227.

Krisko, A. \& Radman, M. 2010. Protein damage and death by radiation in Escherichia coli and Deinococcus radiodurans. Proceedings of the National Academy of Sciences 107: 14373-14377.

Kumar, J., Babele, P.K., Singh, D. \& Kumar, A. 2016. UV-B Radiation Stress Causes Alterations in Whole Cell Protein Profile and Expression of Certain Genes in the Rice Phyllospheric Bacterium Enterobacter cloacae. Frontiers in microbiology 7: 1440.

Larsen, N., Boye, M., Siegumfeldt, H. \& Jakobsen, M. 2006. Differential expression of proteins and genes in the lag phase of Lactococcus lactis subsp. lactis grown in synthetic medium and reconstituted skim milk. Appl. Environ. Microbiol. 72: 1173-1179.

Lin, W.-H. \& Kussell, E. 2016. Complex interplay of physiology and selection in the emergence of antibiotic resistance. Current Biology 26: 1486-1493.

Lindqvist, R. \& Barmark, G. 2014. Specific growth rate determines the sensitivity of Escherichia coli to lactic acid stress: implications for predictive microbiology. BioMed research international 2014.

Long, A., Liti, G., Luptak, A. \& Tenaillon, O. 2015. Elucidating the molecular architecture of adaptation via evolve and resequence experiments. Nature Reviews Genetics 16: 567-582.

Macomber, L. \& Hausinger, R.P. 2011. Mechanisms of nickel toxicity in microorganisms. Metallomics 3: $1153-1162$.

Majtan, T., Frerman, F.E. \& Kraus, J.P. 2011. Effect of cobalt on Escherichia coli metabolism and metalloporphyrin formation. Biometals 24: 335-347.

Makarova, K.S., Aravind, L., Wolf, Y.I., Tatusov, R.L., Minton, K.W., Koonin, E.V. \& Daly, M.J. 2001. Genome of the extremely radiation-resistant bacterium Deinococcus radiodurans viewed from the perspective of comparative genomics. Microbiology and molecular biology reviews 65: 4479.

Markham, B.E., Harper, J.E. \& Mount, D.W. 1985. Physiology of the SOS response: kinetics of lexA and recA transcriptional activity following induction. Molecular and General Genetics MGG 198: 207212.

Maslowska, K.H., Makiela-Dzbenska, K. \& Fijalkowska, I.J. 2019. The SOS system: a complex and tightly regulated response to DNA damage. Environmental and molecular mutagenesis 60: 368-384.

May, K.L. \& Grabowicz, M. 2018. The bacterial outer membrane is an evolving antibiotic barrier. Proceedings of the National Academy of Sciences 115: 8852-8854.

Monod, J. 1949. The growth of bacterial cultures. Annual review of microbiology 3: 371-394. 
Morimatsu, K. \& Kowalczykowski, S.C. 2014. RecQ helicase and RecJ nuclease provide complementary functions to resect DNA for homologous recombination. Proceedings of the National Academy of Sciences 111: E5133-E5142.

Morton, R. \& Haynes, R. 1969. Changes in the ultraviolet sensitivity of Escherichia coli during growth in batch cultures. Journal of bacteriology 97: 1379-1385.

Perez, V., Hengst, M., Kurte, L., Dorador, C., Jeffrey, W.H., Wattiez, R., Molina, V. \& Matallana-Surget, S. 2017. Bacterial Survival under Extreme UV Radiation: A Comparative Proteomics Study of Rhodobacter sp., Isolated from High Altitude Wetlands in Chile. Frontiers in Microbiology 8: 1173.

Prudhomme, M., Attaiech, L., Sanchez, G., Martin, B. \& Claverys, J.-P. 2006. Antibiotic stress induces genetic transformability in the human pathogen Streptococcus pneumoniae. Science 313: 89-92.

Rechinger, K.B., Siegumfeldt, H., Svendsen, I. \& Jakobsen, M. 2000. „Early” protein synthesis of Lactobacillus delbrueckii ssp. bulgaricus in milk revealed by [35S] methionine labeling and twodimensional gel electrophoresis. ELECTROPHORESIS: An International Journal 21: 2660-2669.

Rodríguez-Rojas, A., Kim, J.J., Johnston, P.R., Makarova, O., Eravci, M., Weise, C., Hengge, R. \& Rolff, J. 2020. Non-lethal exposure to $\mathrm{H} 2 \mathrm{O} 2$ boosts bacterial survival and evolvability against oxidative stress. PLoS genetics 16: e1008649.

Rogozin, I.B., Makarova, K.S., Natale, D.A., Spiridonov, A.N., Tatusov, R.L., Wolf, Y.I., Yin, J. \& Koonin, E.V. 2002. Congruent evolution of different classes of non-coding DNA in prokaryotic genomes. Nucleic acids research 30: 4264-4271.

Rohlf, J. \& Sokal, R.R. 1980. Biometry: the principles and practice of statistics in biological research. WH Freeman and company.

Rolfe, M.D., Rice, C.J., Lucchini, S., Pin, C., Thompson, A., Cameron, A.D., Alston, M., Stringer, M.F., Betts, R.P., Baranyi, J., Peck, M.W. \& Hinton, J.C. 2012. Lag phase is a distinct growth phase that prepares bacteria for exponential growth and involves transient metal accumulation. Journal of bacteriology 194: 686-701.

Rosenblum, E.B., Parent, C.E. \& Brandt, E.E. 2014. The molecular basis of phenotypic convergence. Annual Review of Ecology, Evolution, and Systematics 45: 203-226.

Santos, A.L., Moreirinha, C., Lopes, D., Esteves, A.C., Henriques, I., Almeida, A., Domingues, M.R.r.M., Delgadillo, I., Correia, A.n. \& Cunha, A.n. 2013. Effects of UV radiation on the lipids and proteins of bacteria studied by mid-infrared spectroscopy. Environmental science \& technology 47: 63066315.

Schimel, J., Balser, T.C. \& Wallenstein, M. 2007. Microbial stress-response physiology and its implications for ecosystem function. Ecology 88: 1386-1394.

Schlesinger, D.J. 2007. Role of RecA in DNA damage repair in Deinococcus radiodurans. FEMS microbiology letters 274: 342-347.

Schlötterer, C., Kofler, R., Versace, E., Tobler, R. \& Franssen, S. 2015. Combining experimental evolution with next-generation sequencing: a powerful tool to study adaptation from standing genetic variation. Heredity 114: 431-440.

Schwarz, T. 1998. UV light affects cell membrane and cytoplasmic targets. Journal of Photochemistry and Photobiology B: Biology 44: 91-96.

Sherman, B.T. \& Lempicki, R.A. 2009. Systematic and integrative analysis of large gene lists using DAVID bioinformatics resources. Nature protocols 4: 44.

Shibai, A., Takahashi, Y., Ishizawa, Y., Motooka, D., Nakamura, S., Ying, B.W. \& Tsuru, S. 2017. Mutation accumulation under UV radiation in Escherichia coli. Scientific reports 7: 14531.

Shinohara, T., Ikawa, S., Iwasaki, W., Hiraki, T., Hikima, T., Mikawa, T., Arai, N., Kamiya, N. \& Shibata, T. 2015. Loop L1 governs the DNA-binding specificity and order for RecA-catalyzed reactions in homologous recombination and DNA repair. Nucleic acids research 43: 973-986. 
Singh, S.K., SaiSree, L., Amrutha, R.N. \& Reddy, M. 2012. Three redundant murein endopeptidases catalyse an essential cleavage step in peptidoglycan synthesis of E scherichia coli K 12. Molecular microbiology 86: 1036-1051.

Smith, K.C., Wang, T.-C.V. \& Sharma, R.C. 1987. recA-dependent DNA repair in UV-irradiated Escherichia coli. Journal of Photochemistry and Photobiology B: Biology 1: 1-11.

Sprouffske, K., Aguilar-Rodríguez, J., Sniegowski, P. \& Wagner, A. 2018. High mutation rates limit evolutionary adaptation in Escherichia coli. PLoS genetics 14: e1007324.

Sukhi, S.S., Shashidhar, R., Kumar, S.A. \& Bandekar, J.R. 2009. Radiation resistance of Deinococcus radiodurans $\mathrm{R} 1$ with respect to growth phase. FEMS microbiology letters 297: 49-53.

Sullivan, G.M. \& Feinn, R. 2012. Using effect size-or why the $P$ value is not enough. Journal of graduate medical education 4: 279-282.

Sun, D.-W. 2011. Handbook of food safety engineering. Wiley Online Library.

Szostkova, M., Horakova, D. \& Němec, M. 1999. The influence of the growth phase of enteric bacteria on electrotransformation with plasmid DNA. Folia microbiologica 44: 177-180.

Tenaillon, O., Rodríguez-Verdugo, A., Gaut, R.L., McDonald, P., Bennett, A.F., Long, A.D. \& Gaut, B.S. 2012. The molecular diversity of adaptive convergence. Science 335: 457-461.

Tom, E.F., Molineux, I.J., Paff, M.L. \& Bull, J.J. 2018. Experimental evolution of UV resistance in a phage. PeerJ 6: e5190.

Trautinger, B.W., Jaktaji, R.P., Rusakova, E. \& Lloyd, R.G. 2005. RNA polymerase modulators and DNA repair activities resolve conflicts between DNA replication and transcription. Molecular cell 19: 247-258.

Venkateswaran, A., McFarlan, S.C., Ghosal, D., Minton, K.W., Vasilenko, A., Makarova, K., Wackett, L.P. \& Daly, M.J. 2000. Physiologic determinants of radiation resistance inDeinococcus radiodurans. Applied and environmental microbiology 66: 2620-2626.

Voet, D. \& Voet, J.G. 2011. Biochemistry, 4-th Edition. NewYork: John Wiley\& SonsInc.

Wagner, A. 2005. Robustness, evolvability, and neutrality. FEBS letters 579: 1772-1778.

Wang, D., Kreutzer, D.A. \& Essigmann, J.M. 1998. Mutagenicity and repair of oxidative DNA damage: insights from studies using defined lesions. Mutation Research/Fundamental and Molecular Mechanisms of Mutagenesis 400: 99-115.

Wassmann, M., Moeller, R., Reitz, G. \& Rettberg, P. 2010. Adaptation of Bacillus subtilis cells to Archeanlike UV climate: relevant hints of microbial evolution to remarkably increased radiation resistance. Astrobiology 10: 605-615.

Wassmann, M., Moeller, R., Reitz, G. \& Rettberg, P. 2011. Growth phase-dependent UV-C resistance of Bacillus subtilis: data from a short-term evolution experiment. Archives of microbiology 193: 823-832.

Weigand, M.R. \& Sundin, G.W. 2009. Long-term effects of inducible mutagenic DNA repair on relative fitness and phenotypic diversification in Pseudomonas cichorii 302959. Genetics 181: 199-208.

White, O., Eisen, J.A., Heidelberg, J.F., Hickey, E.K., Peterson, J.D., Dodson, R.J., Haft, D.H., Gwinn, M.L., Nelson, W.C. \& Richardson, D.L. 1999. Genome sequence of the radioresistant bacterium Deinococcus radiodurans R1. Science 286: 1571-1577.

Woods, R., Schneider, D., Winkworth, C.L., Riley, M.A. \& Lenski, R.E. 2006. Tests of parallel molecular evolution in a long-term experiment with Escherichia coli. Proceedings of the National Academy of Sciences 103: 9107-9112.

Yang, Z. \& Bielawski, J.P. 2000. Statistical methods for detecting molecular adaptation. Trends in ecology \& evolution 15: 496-503. 
bioRxiv preprint doi: https://doi.org/10.1101/2021.01.05.425512; this version posted January 6, 2021. The copyright holder for this preprint (which was not certified by peer review) is the author/funder. All rights reserved. No reuse allowed without permission. 


\section{Supplementary material}

Figure S1. An overview of the experimental design in this study.

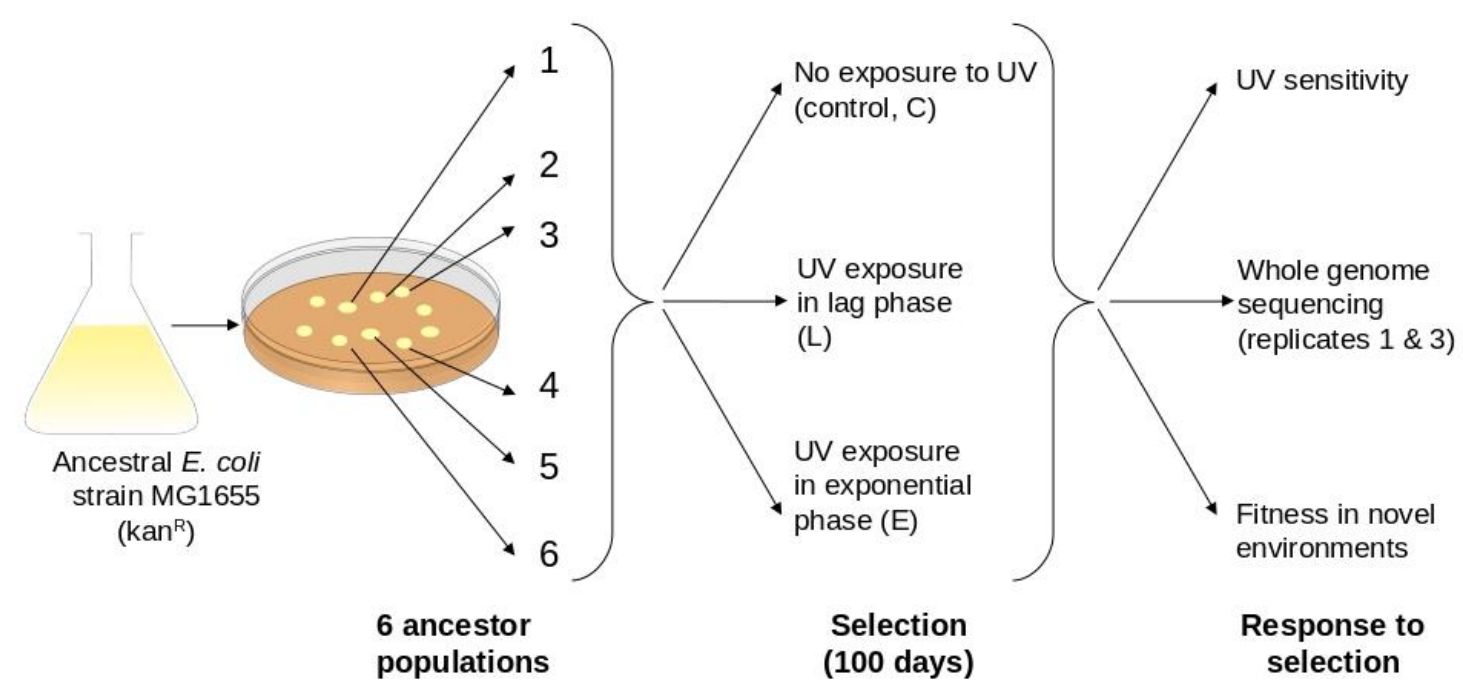




\section{Table S2. Exposure duration during selection}

The duration of exposure to UV was increased every 5 days.

\begin{tabular}{|c|c|}
\hline Days & UV exposure duration (seconds) \\
\hline $1-5$ & 15 \\
\hline $6-10$ & 20 \\
\hline $11-15$ & 25 \\
\hline $16-20$ & 35 \\
\hline $21-25$ & 45 \\
\hline $26-30$ & 60 \\
\hline $31-35$ & 75 \\
\hline $36-40$ & 90 \\
\hline $41-45$ & 110 \\
\hline $46-50$ & 130 \\
\hline $51-55$ & 160 \\
\hline $56-60$ & 200 \\
\hline $61-65$ & 220 \\
\hline $66-70$ & 240 \\
\hline $71-75$ & 270 \\
\hline $76-80$ & 300 \\
\hline $81-85$ & 330 \\
\hline $86-90$ & 340 \\
\hline $91-95$ & 350 \\
\hline $96-100$ & 370 \\
\hline
\end{tabular}


Table S3. Composition of Nutrient broth -

\begin{tabular}{|l|l|}
\hline Ingredients & Gms/litre \\
\hline Peptic digest of animal tissue & 5.00 \\
\hline Sodium chloride & 5.00 \\
\hline Beef extract & 1.50 \\
\hline Yeast extract & 1.50 \\
\hline
\end{tabular}

Final pH (at $\left.25^{\circ} \mathrm{C}\right) 7.4 \pm 0.2$

$\mathrm{NB}^{\mathrm{Kan}}$ was prepared by adding $0.05 \mathrm{mg} / \mathrm{ml}$ of Kanamycin after autoclaving and cooling.

Nutrient Agar ${ }^{\mathrm{Kan}}$ was prepared by adding $2 \mathrm{~g} / 100 \mathrm{ml}$ of agar before autoclaving. 


\section{Table S4. Composition of M9 media}

The growth rate of the selected populations were measured in five minimal media (M9) with fructose, glycose, glycerol, mannose and thymine as single carbon source.

\begin{tabular}{|l|l|}
\hline Ingredients & Gms/litre \\
\hline $\mathrm{NaH} 2 \mathrm{PO} 4.7 \mathrm{H} 2 \mathrm{O}$ & 12.8 \\
\hline $\mathrm{KH} 2 \mathrm{PO} 4$ & 3.0 \\
\hline $\mathrm{NaCl}$ & 0.5 \\
\hline $\mathrm{NH} 4 \mathrm{Cl}$ & 1.0 \\
\hline $\mathrm{MgSO} 4$ & 0.24 \\
\hline $\mathrm{CaCl}_{2}$ & 0.01 \\
\hline Carbon source & 4 \\
\hline
\end{tabular}

$0.05 \mathrm{mg} / \mathrm{ml}$ of Kanamycin was added after autoclaving and cooling. 


\section{Table S5. Mutational spectrum of all SNPs}

The mutational spectrum of all SNPs, including synonymous and non-synonymous mutations, identified in the selected populations in the coding regions (intergenic regions). The spectrum of two replicates (1 and 3) of lag (L), exponential (E) and control (C) populations are listed below.

\begin{tabular}{|c|c|c|c|c|c|c|c|}
\hline \multicolumn{2}{|c|}{ Mutation type } & L1 & L3 & E1 & E3 & C1 & C3 \\
\hline \multirow{4}{*}{ Transition } & $\underset{\mathrm{G}}{\mathrm{A} \rightarrow}$ & $14(3)$ & $12(2)$ & $5(1)$ & $16(9)$ & $0(0)$ & $0(0)$ \\
\hline & $\mathrm{T} \rightarrow \mathrm{C}$ & $12(2)$ & $11(2)$ & $7(2)$ & $18(6)$ & $0(0)$ & $1(0)$ \\
\hline & $\begin{array}{c}\mathrm{G} \rightarrow \\
\mathrm{A}\end{array}$ & $38(14)$ & 107 (22) & $18(2)$ & $80(31)$ & $0(2)$ & $1(1)$ \\
\hline & $\mathrm{C} \rightarrow \mathrm{T}$ & $60(9)$ & $84(15)$ & $8(2)$ & $65(13)$ & $1(1)$ & $0(1)$ \\
\hline \multirow{8}{*}{$\begin{array}{c}\text { Transversio } \\
n\end{array}$} & $\mathrm{G} \rightarrow \mathrm{T}$ & $6(1)$ & $11(1)$ & $0(1)$ & $8(3)$ & $0(0)$ & $0(0)$ \\
\hline & $\mathrm{C} \rightarrow \mathrm{A}$ & $5(0)$ & $8(3)$ & $3(0)$ & $11(2)$ & $0(0)$ & $0(0)$ \\
\hline & $\mathrm{A} \rightarrow \mathrm{C}$ & $3(0)$ & $2(0)$ & $1(2)$ & $4(0)$ & $2(1)$ & $2(0)$ \\
\hline & $\mathrm{T} \rightarrow \mathrm{G}$ & $2(1)$ & $6(1)$ & $1(0)$ & $4(2)$ & $0(0)$ & $2(0)$ \\
\hline & $\mathrm{G} \rightarrow \mathrm{C}$ & $0(1)$ & $2(0)$ & $0(1)$ & $1(0)$ & $0(0)$ & $0(0)$ \\
\hline & $\mathrm{C} \rightarrow \mathrm{G}$ & $2(2)$ & $3(1)$ & $0(0)$ & $4(0)$ & $0(0)$ & $0(0)$ \\
\hline & $\mathrm{A} \rightarrow \mathrm{T}$ & $8(5)$ & $6(2)$ & $2(0)$ & $15(5)$ & $0(0)$ & $2(0)$ \\
\hline & $\mathrm{T} \rightarrow \mathrm{A}$ & $2(3)$ & $13(3)$ & $3(1)$ & $13(9)$ & $0(1)$ & $2(0)$ \\
\hline \multicolumn{2}{|l|}{ Total } & $152(41)$ & $265(52)$ & $48(12)$ & $239(80)$ & $3(5)$ & $10(3)$ \\
\hline
\end{tabular}




\section{Table S6. Functional categorization and enrichment analysis using DAVID}

The list of genes that were unique to each treatment population categorized into functional groups using DAVID. The enrichment analysis did not yield significant results as seen from the fold enrichment and Bonferroni p-values (corrected for inflated family-wise error rates). This could be a result of the high proportion $(\sim 50 \%)$ of ungrouped genes.

\begin{tabular}{|c|c|c|c|c|c|c|}
\hline & $\begin{array}{c}\text { UniProt } \\
\text { Keywords }\end{array}$ & $\begin{array}{l}\text { No. of } \\
\text { genes }\end{array}$ & Gene name & $\begin{array}{c}\text { p- } \\
\text { Value }\end{array}$ & $\begin{array}{c}\text { Fold } \\
\text { Enrichment }\end{array}$ & Bonferroni \\
\hline \multirow{4}{*}{ L1 } & Transport & 21 & $\begin{array}{l}\text { YEHB, DCTA, YFDV, PLAP, } \\
\text { HYCB, FRVA, ADIC, CAIT, } \\
\text { AMPG, MURJ, MLAE, } \\
\text { XAPB, FTSW, YTFR, YJEH, } \\
\text { PROV, ARAE, GLNP, CUSC, } \\
\text { MACB, ACRD }\end{array}$ & 0.04873 & 1.50274896 & 0.9952293 \\
\hline & Membrane & 30 & $\begin{array}{l}\text { YBHM, YQJA, AMPG, } \\
\text { YEAQ, MURJ, MLAE, } \\
\text { FTSW, YAFT, ATOS, YJEH, } \\
\text { PROV, BSMA, GLNP, YIAT, } \\
\text { MACB, ACRD, YEHB, } \\
\text { DCTA, YFDV, CBRB, PLAP, } \\
\text { ADIC, CAIT, DAMX, PLSB, } \\
\text { XAPB, YEJM, ARAE, EVGS, } \\
\text { CUSC }\end{array}$ & 0.06482 & 1.32208262 & 0.9992315 \\
\hline & Ligase & 5 & $\begin{array}{l}\text { PANC, GLUQ, GLYS, QUEC, } \\
\text { FOLC }\end{array}$ & 0.09765 & 2.81182065 & 0.9999832 \\
\hline & Ungrouped & 47 & $\begin{array}{l}\text { AEGA, AHPF, ASTD, BISC, } \\
\text { CAS3, CHIA, DADX, DGT, } \\
\text { DSBA, ELFD, FUMA, FUSA, } \\
\text { HCAB, HSDS, INSG, LPXC, } \\
\text { LRHA, MENC, MRP, NADC, } \\
\text { NAGC, PPNN, PRIC, PUTA, } \\
\text { RECJ, RFBA, RPOC, SMG, } \\
\text { YAAI, YABR, YACH, YAIL, } \\
\text { YCJW, YDDL, YDEP, YEBB, } \\
\text { YEBK, YFDE, YGGF, YGID, } \\
\text { YHJJ, YIAU, YIHM, YJFJ, } \\
\text { YLBG, YPHB, ZINT }\end{array}$ & - & & \\
\hline \multirow{3}{*}{ L3 } & Acetylation & 10 & $\begin{array}{l}\text { ALAS, RPLL, GUAB, THRS, } \\
\text { RPOB, RPLE, ADHE, PYKA, } \\
\text { MANX, SODB }\end{array}$ & 0.0051 & 3.02624845 & 0.5377472 \\
\hline & tRNA-binding & 5 & $\begin{array}{l}\text { ALAS, MNMA, TMCA, } \\
\text { RPLE, DUSC }\end{array}$ & 0.00673 & 6.38143694 & 0.6391871 \\
\hline & $\begin{array}{l}\text { Exopolysaccharide } \\
\text { synthesis }\end{array}$ & 3 & WZA, RFFH, WZC & 0.01062 & 17.612766 & 0.8006331 \\
\hline
\end{tabular}




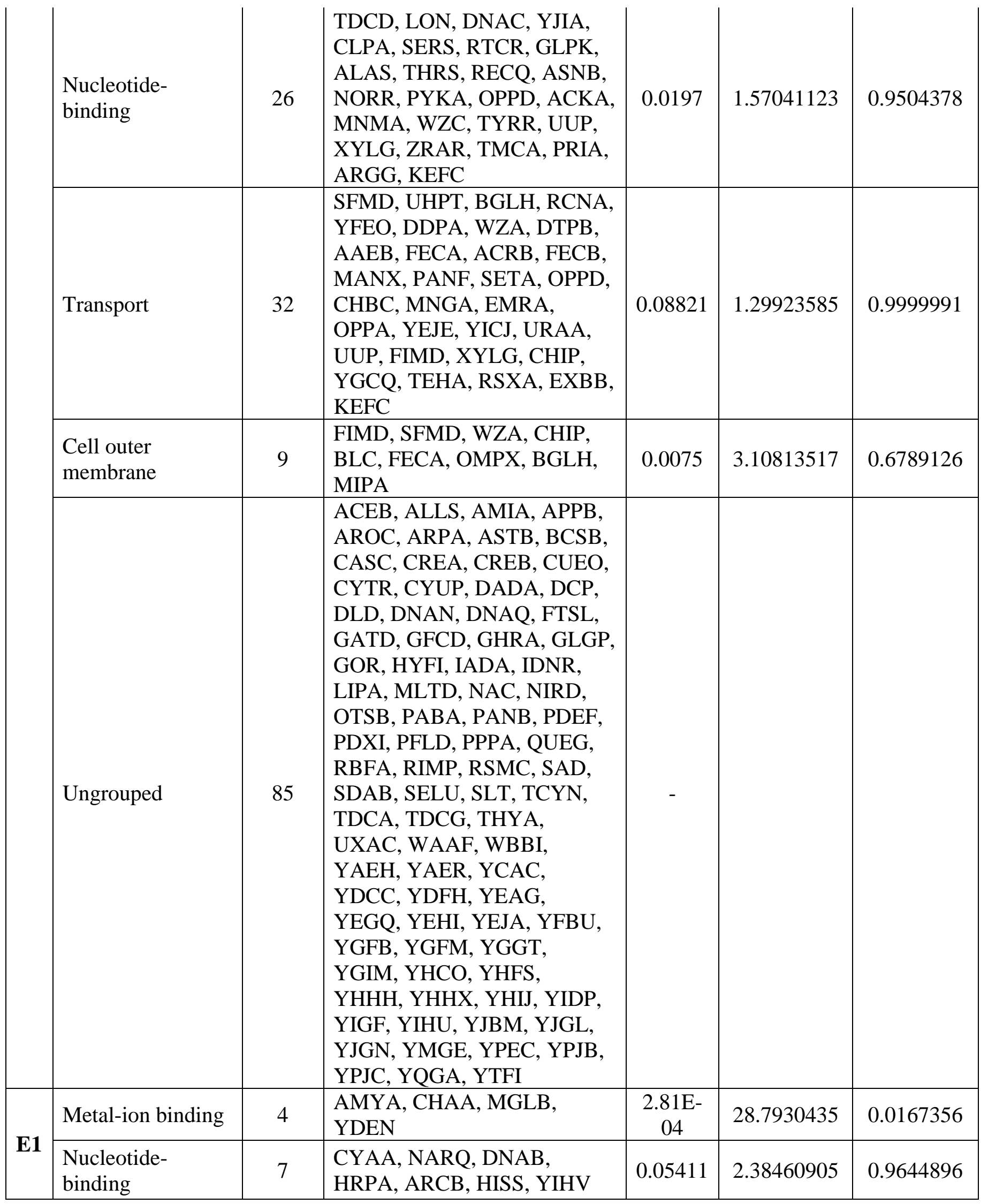




\begin{tabular}{|c|c|c|c|c|c|c|}
\hline & Kinase & 4 & \multirow{2}{*}{$\begin{array}{l}\text { NARQ, ARCB, YIHV, FRYA } \\
\text { CUEO, CYUA, GHXQ, GSIC, } \\
\text { LEPB, MDTE, RSXC, SAD, } \\
\text { SBCD, TDCE, YAAA, YDDL, } \\
\text { YDEE, YDHU, YHDP, YPAB }\end{array}$} & \multirow[t]{2}{*}{0.06819} & \multirow[t]{2}{*}{4.01357576} & \multirow[t]{2}{*}{0.9855589} \\
\hline & Ungrouped & 16 & & & & \\
\hline & Serine esterase & 3 & YPFH, YQIA, YEIG & 0.02751 & 11.1263441 & 0.9792875 \\
\hline & Cell membrane & 39 & $\begin{array}{l}\text { YDDG, ALAE, AMPG, } \\
\text { ENVZ, FETB, ELAB, YDDW, } \\
\text { YJGN, UIDB, CSGD, NFRB, } \\
\text { EPTC, YBBW, CDH, YJEM, } \\
\text { ATPA, UACT, YJHB, NUOM, } \\
\text { YAEF, WCAD, CYSA, } \\
\text { RHTB, UGPE, HYFF, LIVH, } \\
\text { GFCB, CCMA, YDGA, } \\
\text { LIVM, MRDB, SDHC, NUPX, } \\
\text { FLIG, POTB, HFLK, PNUC, } \\
\text { KEFC, KCH }\end{array}$ & 0.09658 & 1.23743561 & 0.9999993 \\
\hline & $\begin{array}{l}\text { Pyridoxal } \\
\text { phosphate binding }\end{array}$ & 5 & $\begin{array}{l}\text { LTAE, ADIA, CYSK, ALR, } \\
\text { YGGS }\end{array}$ & 0.09696 & 2.82873155 & 0.9999993 \\
\hline $\mathbf{E 3}$ & Ungrouped & 80 & $\begin{array}{l}\text { ACEF, ARAF, ASMA, BAER, } \\
\text { CAIC, CAIE, CARB, CASA, } \\
\text { CHBF, CLPB, CSPH, DAPB, } \\
\text { DGOD, DNAE, ELAD, } \\
\text { FABR, FDNG, FIMH, FUCR, } \\
\text { GLMS, GLMU, GLPD, } \\
\text { GLTB, GSHB, HMP, HXPB, } \\
\text { LPTD, MALQ, METF, MQO, } \\
\text { OPGG, PDHR, PHEM, PNP, } \\
\text { PURN, RAPA, RDGB, RECJ, } \\
\text { RHAB, RHSB, RIMJ, RLMA, } \\
\text { RNB, RNK, RPMG, RPOC, } \\
\text { SELU, SRLR, STPA, TORZ, } \\
\text { TREA, UUP, VIAA, XSEA, } \\
\text { YBHH, YCCT, YCHS, YCIA, } \\
\text { YCIE, YCIF, YCJT, YCJW, } \\
\text { YCJX, YDBD, YDIF, YDJO, } \\
\text { YEEJ, YEJK, YFBK, YGIF, } \\
\text { YHCO, YHHX, YIAJ, YIGL, } \\
\text { YJGL, YJJQ, YKFM, YMGD, } \\
\text { YPFJ, ZAPA }\end{array}$ & - & & \\
\hline
\end{tabular}




\section{Table S7. UV sensitivity values}

UV sensitivity of the evolved, control and ancestral population when exposed to 370 seconds of UV.

\begin{tabular}{|l|l|l|r|r|}
\hline Trial & $\begin{array}{l}\text { Assay- } \\
\text { Growth } \\
\text { phase }\end{array}$ & $\begin{array}{l}\text { Selection- } \\
\text { Growth } \\
\text { phase }\end{array}$ & Replicate & $\begin{array}{l}\text { UV induced } \\
\text { logiv reduction }\end{array}$ \\
\hline I & Lag & Lag & 1 & 0.836497868 \\
\hline I & Lag & Lag & 2 & 0.954471146 \\
\hline I & Lag & Lag & 3 & 0.726998728 \\
\hline I & Lag & Lag & 4 & 0.466263327 \\
\hline I & Lag & Lag & 5 & 1.093049592 \\
\hline I & Lag & Lag & 6 & 0.434410528 \\
\hline II & Lag & Lag & 1 & 1.029383778 \\
\hline II & Lag & Lag & 2 & 1.761117911 \\
\hline II & Lag & Lag & 3 & 0.645838916 \\
\hline II & Lag & Lag & 4 & 0.00152652 \\
\hline II & Lag & Lag & 5 & 1.79278894 \\
\hline II & Lag & Lag & 6 & 2.407156813 \\
\hline I & Lag & Exponential & 1 & 1.698970004 \\
\hline I & Lag & Exponential & 2 & 0.812326868 \\
\hline I & Lag & Exponential & 3 & 1.268306151 \\
\hline I & Lag & Exponential & 4 & 1.597943425 \\
\hline I & Lag & Exponential & 5 & 1.12082217 \\
\hline I & Lag & Exponential & 6 & 1.660812302 \\
\hline II & Lag & Exponential & 1 & 2 \\
\hline II & Lag & Exponential & 2 & 1.643922438 \\
\hline II & Lag & Exponential & 3 & 0.672347524 \\
\hline II & Lag & Exponential & 5 & 1.191282758 \\
\hline II & Lag & Exponential & & 2.483281563 \\
\hline II & Lag & Exponential & 618858748 \\
\hline & & & & \\
\hline
\end{tabular}




\begin{tabular}{|c|c|c|c|c|}
\hline I & Lag & Control & 1 & 4.789146635 \\
\hline I & Lag & Control & 2 & 6 \\
\hline I & Lag & Control & 3 & 4.558490387 \\
\hline I & Lag & Control & 4 & 4.853476972 \\
\hline I & Lag & Control & 5 & 5.875061263 \\
\hline I & Lag & Control & 6 & 4.962211439 \\
\hline II & Lag & Control & 1 & 4.768839833 \\
\hline II & Lag & Control & 2 & 4.788455999 \\
\hline II & Lag & Control & 3 & 5.67516709 \\
\hline II & Lag & Control & 4 & 5.818156412 \\
\hline II & Lag & Control & 5 & 7.243038049 \\
\hline II & Lag & Control & 6 & 4.953895213 \\
\hline I & Lag & Ancestor & 1 & 5.736758565 \\
\hline $\mathrm{I}$ & Lag & Ancestor & 2 & 5 \\
\hline I & Lag & Ancestor & 3 & 4.911273436 \\
\hline I & Lag & Ancestor & 4 & 5.780857144 \\
\hline I & Lag & Ancestor & 5 & 5.795880017 \\
\hline I & Lag & Ancestor & 6 & 4.848531216 \\
\hline II & Lag & Ancestor & 1 & 5.836745966 \\
\hline II & Lag & Ancestor & 2 & 5.716003344 \\
\hline II & Lag & Ancestor & 3 & 5.25224605 \\
\hline II & Lag & Ancestor & 4 & 6.176091259 \\
\hline II & Lag & Ancestor & 5 & 7.041392685 \\
\hline II & Lag & Ancestor & 6 & 5.281846679 \\
\hline I & Exponential & Lag & 1 & 2.050609993 \\
\hline I & Exponential & Lag & 2 & 2.965237894 \\
\hline I & Exponential & Lag & 3 & 1.437750563 \\
\hline I & Exponential & Lag & 4 & 1.852323676 \\
\hline I & Exponential & Lag & 5 & 2.30207272 \\
\hline I & Exponential & Lag & 6 & 1.446200644 \\
\hline
\end{tabular}




\begin{tabular}{|c|c|c|c|c|}
\hline II & Exponential & Lag & 1 & 2.105633581 \\
\hline II & Exponential & Lag & 2 & 2.49574251 \\
\hline II & Exponential & Lag & 3 & 1.635261445 \\
\hline II & Exponential & Lag & 4 & 1.897804391 \\
\hline II & Exponential & Lag & 5 & 2.416489212 \\
\hline II & Exponential & Lag & 6 & 1.249877473 \\
\hline $\mathrm{I}$ & Exponential & Exponential & 1 & 2 \\
\hline $\mathrm{I}$ & Exponential & Exponential & 2 & 2.486849858 \\
\hline $\mathrm{I}$ & Exponential & Exponential & 3 & 0.654996067 \\
\hline $\mathrm{I}$ & Exponential & Exponential & 4 & 2.266052412 \\
\hline $\mathrm{I}$ & Exponential & Exponential & 5 & 1.67593102 \\
\hline $\mathrm{I}$ & Exponential & Exponential & 6 & 2.006182232 \\
\hline II & Exponential & Exponential & 1 & 2.817581758 \\
\hline II & Exponential & Exponential & 2 & 4.628057027 \\
\hline II & Exponential & Exponential & 3 & 1.137926523 \\
\hline II & Exponential & Exponential & 4 & 3.696264111 \\
\hline II & Exponential & Exponential & 5 & 1.879979713 \\
\hline II & Exponential & Exponential & 6 & 2.241153905 \\
\hline I & Exponential & Control & 1 & 5.642488648 \\
\hline $\mathrm{I}$ & Exponential & Control & 2 & 7.301029996 \\
\hline $\mathrm{I}$ & Exponential & Control & 3 & 7.694605199 \\
\hline $\mathrm{I}$ & Exponential & Control & 4 & 7.079181246 \\
\hline $\mathrm{I}$ & Exponential & Control & 5 & 7.08754481 \\
\hline I & Exponential & Control & 6 & 7.63973544 \\
\hline II & Exponential & Control & 1 & 6.970897618 \\
\hline II & Exponential & Control & 2 & 6.388248237 \\
\hline II & Exponential & Control & 3 & 7.630427875 \\
\hline II & Exponential & Control & 4 & 6.621365147 \\
\hline II & Exponential & Control & 5 & 6.722908012 \\
\hline II & Exponential & Control & 6 & 6.5633732 \\
\hline
\end{tabular}




\begin{tabular}{|l|l|l|r|r|} 
I & Exponential & Ancestor & 1 & 8.335792102 \\
\hline I & Exponential & Ancestor & 2 & 8.432969291 \\
\hline I & Exponential & Ancestor & 3 & 8.359835482 \\
\hline I & Exponential & Ancestor & 4 & 7.698970004 \\
\hline I & Exponential & Ancestor & 5 & 6.638272164 \\
\hline I & Exponential & Ancestor & 6 & 8.170261715 \\
\hline II & Exponential & Ancestor & 1 & 6.133893579 \\
\hline II & Exponential & Ancestor & 2 & 7.996730515 \\
\hline II & Exponential & Ancestor & 3 & 8.404833717 \\
\hline II & Exponential & Ancestor & 4 & 8.118099312 \\
\hline II & Exponential & Ancestor & 5 & 8.522878745 \\
\hline II & Exponential & Ancestor & 6 & 7.750122527 \\
\hline
\end{tabular}


Figure S8. Distribution of mutation frequency in the UV selected populations.

A histogram showing the distribution of the mutation frequency in the four UV-treated populations.
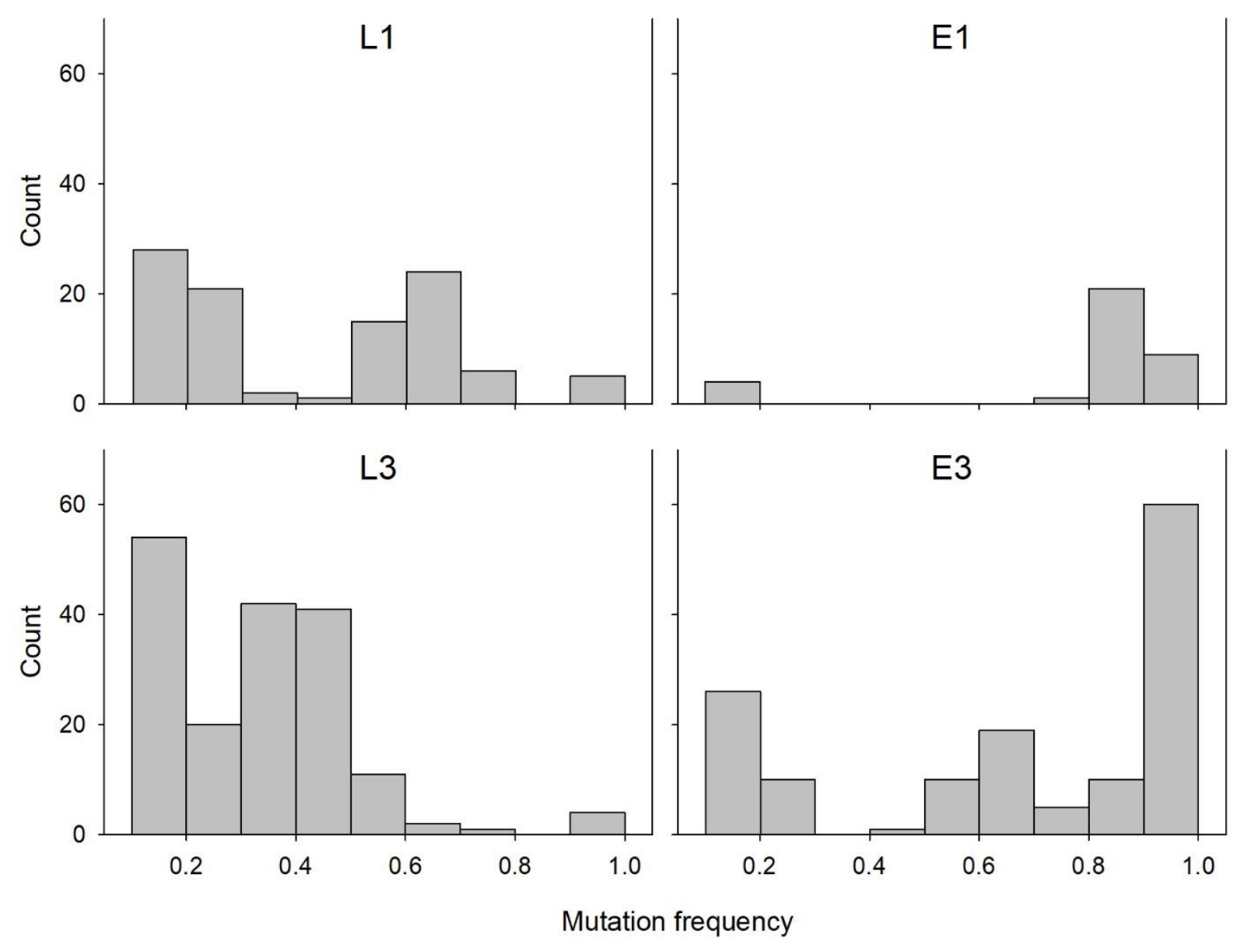